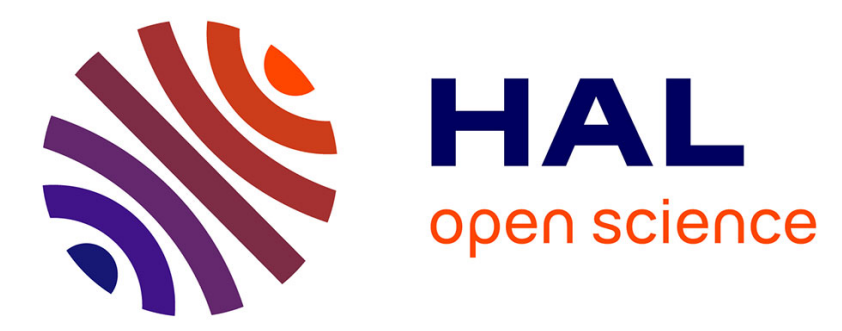

\title{
The BCCT-family of carriers: from physiology to crystal structure
}

\author{
Christine Maria Ziegler, Erhard Bremer, Reinhard Krämer
}

\section{To cite this version:}

Christine Maria Ziegler, Erhard Bremer, Reinhard Krämer. The BCCT-family of carriers: from physiology to crystal structure. Molecular Microbiology, 2010, 10.1111/j.1365-2958.2010.07332.x . hal-00572623

\section{HAL Id: hal-00572623 \\ https://hal.science/hal-00572623}

Submitted on 2 Mar 2011

HAL is a multi-disciplinary open access archive for the deposit and dissemination of scientific research documents, whether they are published or not. The documents may come from teaching and research institutions in France or abroad, or from public or private research centers.
L'archive ouverte pluridisciplinaire HAL, est destinée au dépôt et à la diffusion de documents scientifiques de niveau recherche, publiés ou non, émanant des établissements d'enseignement et de recherche français ou étrangers, des laboratoires publics ou privés. 


\section{molecular microbiology}

\section{The BCCT-family of carriers: from physiology to crystal structure}

\begin{tabular}{|r|l|}
\hline Journal: & Molecular Microbiology \\
\hline Manuscript ID: & MMI-2010-09962.R1 \\
\hline Manuscript Type: & MicroReview \\
\hline Author: & 28-Jul-2010 \\
\hline Complete List of Authors: & $\begin{array}{l}\text { Ziegler, Christine; Max Planck Institute for Biophysics, Frankfurt, } \\
\text { Department of Structural Biology } \\
\text { Bremer, Erhard; University of Marburg, Department of Biology } \\
\text { Krämer, Reinhard; Universitat zu Koeln, Institut fur Biochemie }\end{array}$ \\
\hline Key Words: & $\begin{array}{l}\text { osmoregulation, compatible solutes, crystal structures, ligand } \\
\text { binding, sensing of water stress }\end{array}$ \\
\hline \multicolumn{2}{|l}{} \\
\hline
\end{tabular}


6

7

\section{The BCCT-family of carriers: from physiology to crystal structure}

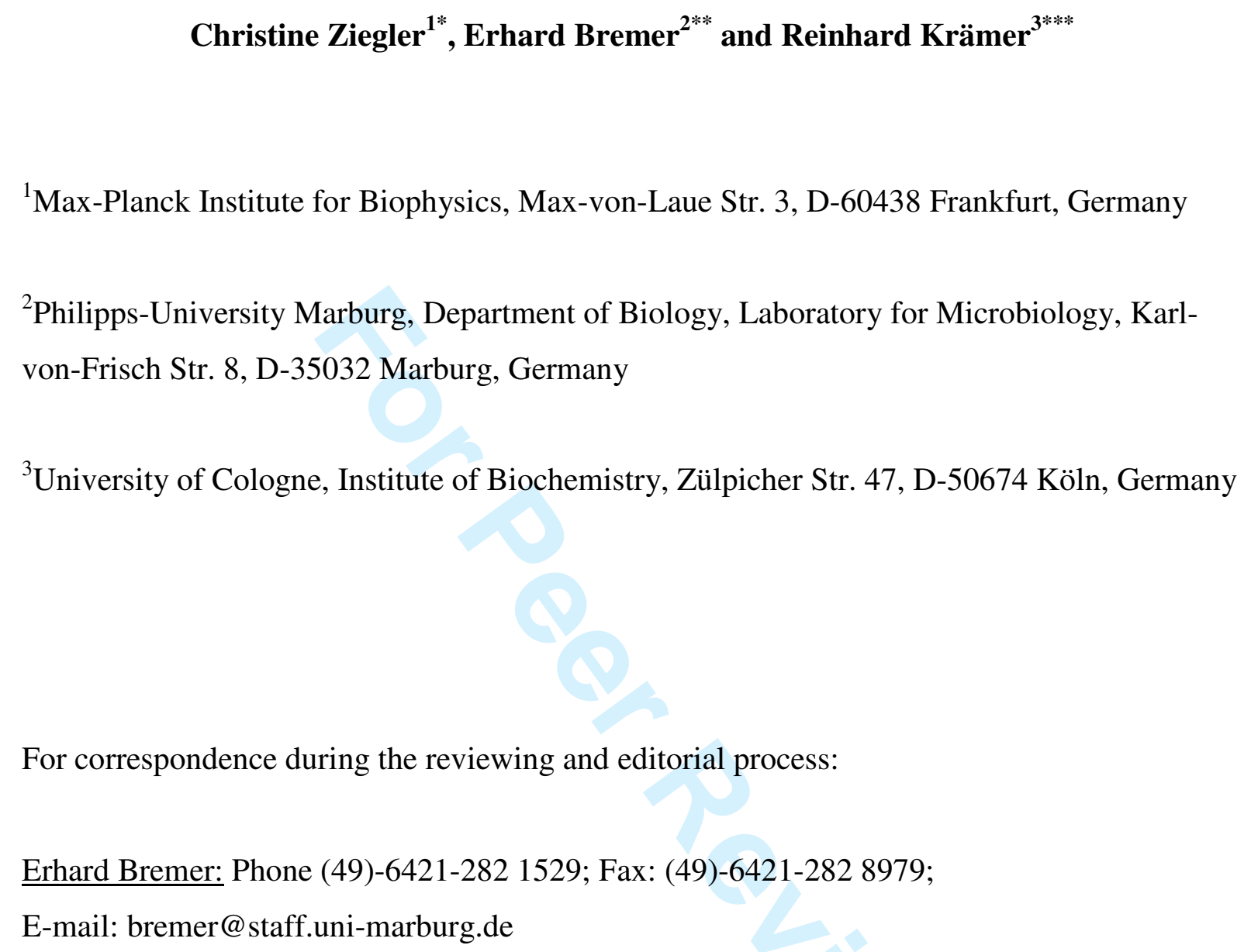

Erhard Bremer: Phone (49)-6421-282 1529; Fax: (49)-6421-282 8979;

E-mail: bremer@staff.uni-marburg.de

Key words: Osmoregulation - compatible solutes - sodium- and proton-coupled transporters - antiporters - sensing of water stress - ligand binding

For correspondence. *E-mail christine.ziegler@biophys.mpg.de; Tel. (+49)-69-6303-3054; Fax (+49)-69-6303-2209; **E-mail bremer@staff.uni-marburg.de; Tel. (49)-6421-282-1529; Fax (49)-6421-282 8979; ***E-mail r.kraemer@uni-koeln.de; Tel. (+49)-221-470-6461; Fax (+49)-221-470-5091 


\section{Summary}

Increases in the environmental osmolarity are key determinants for the growth of microorganisms. To ensure a physiologically acceptable level of cellular hydration and turgor at high osmolarity, many bacteria accumulate compatible solutes. Osmotically controlled uptake systems allow the scavenging of these compounds from scarce environmental sources as effective osmoprotectants. A number of these systems belong to the BCCT family (betainecholine-carnitine-transporter), sodium- or proton-coupled transporters (e.g. BetP and BetT, respectively) that are ubiquitous in microorganisms. The BCCT family also contains CaiT, a L-carnitine $/ \gamma$-butyrobetaine antiporter that is not involved in osmotic stress responses. The glycine betaine transporter BetP from Corynebacterium glutamicum is a representative for osmoregulated symporters of the BCCT-family and functions both as an osmosensor and osmoregulator. The crystal structure of BetP in an occluded conformation in complex with its substrate glycine betaine and two crystal structures of CaiT in an inward-facing open conformation in complex with L-carnitine and $\gamma$-butyrobetaine were reported recently. These structures, and the wealth of biochemical data on the activity control of BetP in response to osmotic stress enables a correlation between the sensing of osmotic stress by a transporter protein with the ensuing regulation of transport activity. Molecular determinants governing the high-affinity binding of the compatible solutes by BetP and CaiT, the coupling in symporters and antiporters, and the osmoregulatory properties are discussed in detail for BetP and various BCCT carriers.

(2)


69

70

71

72

\section{Introduction}

One of the key parameters affecting the survival and growth of microorganisms are changes in the osmotic conditions of their habitat (Kempf and Bremer, 1998; Wood et al., 2001; Poolman et al., 2002; Altendorf et al., 2009; Hagemann, 2010). Exposure of the cell to either hypo- or hyper-osmotic surroundings triggers rapid water fluxes across the semi-permeable cytoplasmic membrane (Fig. 1) whose direction is determined by the differential in osmotic potential between the cell's interior and the environment (Wood, 1999; Bremer and Krämer, 2000; Altendorf et al., 2009). Both the osmotically instigated water fluxes and the resulting changes in turgor, an intracellular hydrostatic pressure, impinge on many physiological processes (Record et al., 1998; Wood, 1999). AqpZ-type aquaporins that are present in a substantial number of microorganisms mediate accelerated water fluxes across the cytoplasmic membrane in response to osmotic gradients (Tanghe et al., 2006). However, these types of water channels are not essential for water fluxes across the cell membrane in bacteria. Most importantly, no single microorganism can actively transport water into or out of the cell. But microorganisms can actively influence the direction of water fluxes across the cell membrane in response to hyper- or hypo-osmotic conditions. They do so by indirectly determining the scale of the osmotically driven water fluxes across the cytoplasmic membrane by actively adjusting the osmotic potential of their interior via active control of their ion and organic solute pools (Fig. 1).

\section{Environmental osmotic up- and downshifts and compensatory microbial reactions}

Exposure of a microbial cell to a hypo-osmotic surrounding triggers rapid water influx (Fig. 1). In extreme cases, water entry can drive up turgor to such magnitudes that the stressbearing peptidoglycan sacculus can no longer cope with it and the cell is threaten to bursts (Booth et al., 2007). To avoid such a catastrophic event, mechanosensitive channels are transiently opened as safety valves through which both solutes and solvents can pass rapidly (Perozo, 2006; Martinac et al., 2008; Anishkin and Sukharev, 2009). Hence, the cell can reduce the osmotic potential of its interior within seconds and thereby curbs water influx and reduces turgor; as a consequence, cell lysis is prevented (Booth et al., 2007).

Exposure of a microbial cell to hyper-osmotic conditions elicits water efflux (Fig. 1), thereby causing dehydration of the cytoplasm, a reduction or even collapse of turgor, and eventually growth arrest (Record et al., 1998). The slowing of cell growth and finally growth arrest are strongly correlated with the diminished amounts of free cytoplasmic water (Cayley and Record, 2003). The cell can increase the content of free cytoplasmic water by raising the 
103 osmotic potential of its interior via accumulation of either ions or organic osmolytes (Kempf

104 and Bremer, 1998; Wood, 1999; Bremer and Krämer, 2000; Wood et al., 2001; Oren, 2008,

105 Altendorf et al., 2009; Hagemann, 2010).

106

\section{Properties of compatible solutes}

108 Many microorganisms accumulate a selected class of organic osmolytes, the compatible 109 solutes, to fend off the detrimental effects of high osmolarity on water content and cell 110 physiology (Kempf and Bremer, 1998; Bremer and Krämer, 2000; Wood et al., 2001; 111 Empadinhas and da Costa, 2008). Compatible solutes are operationally defined as organic 112 osmolytes that can be accumulated to exceedingly high intracellular levels without impairing 113 vital functions of the cell (Kempf and Bremer, 1998; Burg and Ferraris, 2008; Empadinhas 114 and da Costa, 2008). These solutes have biophysical and biochemical properties that 115 distinguish them from other types of organic compounds, and they have been specifically 116 selected during the course of evolution as cytoprotectants in all three kingdoms of life 117 (Yancey et al., 1982; Yancey, 2005). A hallmark of compatible solutes is their preferential exclusion from the immediate hydration shell of proteins (Arakawa and Timasheff, 1985) due to unfavourable interactions between the osmolytes and the protein backbone (Bolen and

120 Rose, 2008). This uneven distribution of compatible solutes in the cell water generates a 121 thermodynamic driving force that promotes the proper conformation of proteins and the 122 formation of protein assemblies, thereby maintaining their biological functions (Bolen and 123 Baskakov, 2001; Ignatova and Gierasch, 2006; Street et al., 2006; Rosgen, 2007; Capp et al., 124 2009; Rosgen, 2009; Street et al., 2010). It should be noted however, that compatible solutes 125 that are ubiquitously used by microorganisms (e.g. proline and glycine betaine) interact differently with protein surfaces (Auton et al., 2008).

\section{Microbial transport systems for compatible solutes}

129 Most microorganisms that adopt the "salt-out" strategy both synthesize and acquire various 130 types of compatible solutes. Osmotically down-shocked or decaying microbial cells (e.g. after 131 viral attack), excretion products of animals and plants (urine and root exudates, respectively) and of algae are sources of these compounds (Welsh, 2000). Compatible solutes are found in very low concentrations (typically in the $\mu \mathrm{M}$ or $\mathrm{nM}$ range) in the environment. To take

134 advantage of these scarce resources as osmostress protectants, microorganisms use 135 osmotically controlled high-affinity uptake systems (Kempf and Bremer, 1998; Wood, 1999; 136 Bremer and Krämer, 2000; Wood et al., 2001; Poolman et al., 2004; Wood, 2006; Krämer, 
2009; Hagemann, 2010). The intracellular level to which compatible solutes are amassed is fine-tuned to the degree of osmotic stress perceived by the microbial cell. Microorganisms can accumulate compatible solutes via transport systems against steep concentration gradients, and intracellular concentrations above one molar can be attained (Peter et al., 1996; Krämer, 2009). Uptake of compatible solutes by microorganisms is energetically favourable over de novo synthesis (Oren, 1999). Furthermore, the uptake of compatible solutes often represses the expression of genes encoding enzymes required for compatible solute synthesis. Transport systems for compatible solutes not only serve to capture these compounds from scarce environmental sources but also serve for the re-import of these compounds leaked from microbial producer cells in high osmolarity surroundings (Lamark et al., 1992; Mikkat and Hagemann, 2000; Grammann et al., 2002).

Frequently, the transcription of the structural genes encoding compatible solute transporters are up-regulated in response to increases in the osmolarity of the environment. Typically, gene expression is rapidly induced after the cells experience an osmotic up-shift, promoter activity being adjusted to the degree of the prevalent osmotic stress (Spiegelhalter and Bremer, 1998; Cheung et al., 2003; Nagarajavel et al., 2007; Romeo et al., 2007; Rosenthal et al., 2008; Altendorf et al., 2009; Krämer, 2010). Furthermore, the activity of the compatible solute transporter itself is often subjected to osmotic control on the level of activity (Wood, 1999; van der Heide and Poolman, 2000; van der Heide et al., 2001; Poolman et al., 2004; Wood, 2006; Krämer, 2009; Mahmood et al., 2009; Romantsov et al., 2009). Thus, microbial uptake systems for compatible solutes are not only effective transporters but they can also sense and respond to osmotic stress themselves. This permits a practically instantaneous physiological response by allowing the osmotically stressed cell to accumulate types of solutes that restrict water loss and that are at the same time congruous with its other physiological needs. By sensitive adjustment of both the amount of the transport protein(s) via gene expression and de novo protein synthesis and the activity of the transporter itself, the bacterial cell can exert maximum control over its cellular compatible solutes pool.

The preferential exclusion of compatible solutes from protein surfaces is a hallmark of the protective function of these types of solutes (Arakawa and Timasheff, 1985; Bolen and Baskakov, 2001; Ignatova and Gierasch, 2006; Street et al., 2006; Rosgen, 2007; Bolen and Rose, 2008; Street et al., 2010). However, in transport systems for compatible solutes, highaffinity interactions between the substrates and proteins have to take place in order to archive effective import. Crystallographic studies with soluble ligand-binding proteins from six ABCand two TRAP-transport systems and the secondary transporters BetP and CaiT have recently 
171 provided insight into how such a task can be accomplished (Schiefner et al., 2004a; Schiefner

172 et al., 2004b; Horn et al., 2006; Oswald et al., 2008; Smits et al., 2008; Ressl et al., 2009;

173 Tang et al., 2010; Schulze et al., 2010; Wolters et al., 2010). In all these systems, aromatic

174 ligand binding boxes of various architectures recognize the bulky head-groups of glycine

175 betaine, choline, L-carnitine, $\gamma$-butyrobetaine and DMSA (Fig. 2) via cation-pi interactions.

176 Hydrogen bonds and salt-bridges then fix and orient the various "tails" of the different 177 substrates (Fig. 2) within the ligand-binding site. Cation-pi interactions also play important 178 roles for the high-affinity binding of ectoine and hydroxyectoine by soluble ligand binding proteins from $\mathrm{ABC}$ - or TRAP-transporters, but due to the chemical features of these compatible solutes (Figure 2), the architecture of the ligand-binding sites is different form those that are used to bind compatible solutes such as glycine betaine, proline betaine and DMSA (Hanekop et al., 2007; Kuhlmann et al., 2008; Lecher et al., 2009).

The types of functionally characterized microbial transporters for compatible solutes include members of the multi-component $\mathrm{ABC}$ (e.g. ProU, OpuA, and Ehu) and TRAP transporter families (Tea and Ueh) and single-component transport systems such as ProP $\left(\mathrm{H}^{+} /\right.$solute symporter; MSF-family), OpuE ( $\mathrm{Na}^{+} /$solute symporter; SSSF-family) and members of the BCCT family (e.g. BetT, BetP, OpuD). The prototypes of these osmotically controlled uptakes systems have been discovered through diligent genetic and physiological studies with just a few bacterial species (Kempf and Bremer, 1998; Bremer and Krämer, 2000; Wood et al., 2001; Bremer, 2002; Altendorf et al., 2009; Krämer, 2009). However, even a cursory inspection of the more than 1000 microbial genome sequences available today shows that compatible solute uptake systems related to those mentioned above are found widely in the domain of the Bacteria and of the Archaea.

Three transporters have been studied in detail by biochemical, biophysical and genetic approaches with the aim of unravelling the mechanism(s) and interplay of their osmoregulatory and transporter function. These are the $\mathrm{ABC}$ transporter $\mathrm{OpuA}$ from Lactococcus lactis, the $\mathrm{H}^{+}$/solute symporter ProP from Escherichia coli and the BCCT carrier

198 BetP from Corynebacterium glutamicum (van der Heide and Poolman, 2000; van der Heide et al., 2001; Poolman et al., 2004; Culham et al., 2008a; Culham et al., 2008b; Krämer, 2009; Mahmood et al., 2009).

The BCCT carrier BetP from C. glutamicum occupies a special position within this group of osmoregulatory compatible solute transport systems because a well-resolved crystal structure of the BetP protein with bound glycine betaine and sodium ligands has been reported (Ressl et al., 2009). Most recently, three X-ray structures of another BCCT-carrier, 
205

206

207

208

209

210

211

212

213

214

215

216

217

218

219

220

the L-carnitine/ $\gamma$-butyrobetaine antiporter CaiT from E. coli and Proteus mirabilis was solved in complex with its substrate L-carnitine and $\gamma$-butyrobetaine (Tang et al., 2010; Schulze et $a l ., 2010)$. The CaiT proteins from these two organisms are not involved in osmostress responses and instead mediate L-carnitine: $\gamma$-butyrobetaine antiport under unaerobic growth conditions (Jung et al., 2002).

The ligand-bound crystal structures of the BCCT carriers BetP (Ressl et al., 2009) and CaiT (Tang et al., 2010; Schulze et al., 2010) reveal common characteristics with respect to their overall fold, their topological organization with the cytoplasmic membrane and the transport function of these proteins. However, distinct features became apparent from these crystal structures that build the foundation for the osmotic control of the transport activity of BetP. Using the structural data of both the BetP and CaiT transporters and a wealth of biochemical data available for BetP (Ott et al., 2008; Krämer, 2009; Ressl et al., 2009) and CaiT (Jung et al., 2002; Schulze et al., 2010) as a point of reference, we will evaluate features for osmotic activity control of BetP to assess the physiological roles of various microbial BCCT carriers.

\section{The BCCT carriers: discovery and general features}

The first member (BetT) of the subsequently christened BCCT transporter family was described almost 20 years ago by Arne R. Strom and co-workers in connection with the genetic analysis of the osmoregulatory choline-to-glycine betaine synthesis pathway of E. coli (Lamark et al., 1991). BetT was shown to mediate the high-affinity uptake of choline, the biosynthetic precursor for the compatible solute glycine betaine. A L-carnitine transporter protein (CaiT) related to the choline transporter BetT was subsequently discovered when the genes involved in L-carnitine metabolism in E. coli were studied (Eichler et al., 1994). The simultaneous discoveries of the OpuD transporter from Bacillus subtilis (Kappes et al., 1996) and BetP from C. glutamicum (Peter et al., 1996), both involved in osmotically controlled glycine betaine uptake, led then Kappes et al. (1996) to propose that the afore-mentioned choline, L-carnitine and glycine betaine transporters form a new transporter sub-family with substrate specificity for various types of trimethylammonium compounds (Fig. 2).

Using the substrates of the BetT, CaiT, OpuD and BetP transporters as a point of reference, Milton Saier's laboratory subsequently grouped these transporters into the BCCT family (betaine-choline-carnitine-transporter) (Saier, 2000) and placed them into sub-group 2.A.15 of the International Union of Biochemistry and Molecular Biology-approved transporter classification (TC) system [http://www.tcdb.org] (Saier et al., 2009). BCCT 
carriers comprise uptake systems that are energized either by proton-motive-force-driven (e.g.

BetT) or sodium-motive-force-driven (e.g. BetP) symport, or more rarely, by substrate:product antiport (e.g. CaiT) (Table 1).

It was originally thought that a unifying feature of BCCT carriers is the transport of substrates with quaternary ammonium groups $\left.\left[\mathrm{R}-\mathrm{N}^{+}(\mathrm{CH})_{3}\right)_{3}\right]$ such as choline, L-carnitine and glycine betaine (Kappes et al., 1996; Saier, 2000) (Fig. 2). In recent years, several new substrates for BCCT carriers have been discovered. Of these, proline betaine, acetylcholine, dimethylsulfoniopropionate (DMSP) and dimethylsulfonioacetate (DMSA) all posses fully methylated nitrogen- or sulfonium headgroups (Fig. 2) and, thus, conform in a wider sense to the originally suggested chemical features of substrates for BCCT carriers. However, the chemical structures of the compatible solutes ectoine and hydroxyectoine (Fig. 2), substrates for BCCT carriers detected in various microbial species (Table 1), do not match this general scheme. In addition, some BCCT-type transporters also mediate proline uptake, but usually with rather low affinity. So far, no functionally characterized BCCT carrier has been described to catalyze the uptake of the full range of currently known substrates (Table 1; Fig. 2). However, for some BCCT carriers competition experiments have been carried out that suggests a rather restricted substate specificity for a given BCCT carrier. For instance, in the halotolerant alakaliphilic cyanobacterium Aphanothece halophytica, the BetT-mediated glycine betaine transport (Table 1) was not inhibited by glycine betaine aldehyde, dimethylglycine, sarchosine, choline or proline (Laloknam et al., 2006).

Physiological functions of BCCT carriers and transcriptional regulation of their structural genes

262 The explosion in the number of available genome sequences of Bacteria and Archaea revealed a widespread distribution of BCCT carriers in the microbial world. Under the entry "IPR000060 BCCT transporter", the InterPro database [http://www.ebi.ac.uk/interpro/] lists currently about 2200 protein sequences. Most of these protein sequences originate from members of the Bacteria and only 22 are from members of the Archaea. The InterPro database also records a limited number of BCCT carriers from Eukarya, but nothing is known about their function.

Most BCCT carriers have a common hydropathy profile with 12 predicted transmembrane (TM)-spanning segments and exhibit $\mathrm{N}$ - and $\mathrm{C}$-terminal extensions of various lengths (Table 1) that are predicted to protrude into the cytoplasm. An important functional role of these $\mathrm{N}$ - and $\mathrm{C}$-terminal domains for the control of transport activity and osmotic 
273 regulation was first discovered for the glycine betaine transporter BetP (Peter et al., 1998a). 274 Subsequent studies with the choline transporters BetT of E. coli (Tondervik and Strom, 2007) 275 and Pseudomonas syringae (Chen and Beattie, 2008), revealed the contribution of the C276 terminal domain for the proper functioning of these BCCT carriers as well. The most conserved part of BCCT carriers comprises TM8 and the connecting loop to TM9 and these segments contain the tryptophane motif that is the signature sequence of BCCT carriers (Kappes et al., 1996; Saier, 2000).

In the Pfam database [http://pfam.sanger.ac.uk/] some physiologically uncharacterized BCCT carrier related proteins are listed that possess additional domains (Usp, CoaE, TrkA_C) or membrane-spanning segments fused to the canonical 12 TM core structure of BCCT carriers. Twenty-two microbial BCCT carriers have so far been functionally characterized at least to some extent (Table 1). Using the $C$. glutamicum BetP glycine betaine transporter protein as the search template, these 22 proteins exhibit a range from $48 \%$ down to $25 \%$ identical amino acid residues (Table 1). However, it should be noted that functionally uncharacterized BCCT carriers can readily be found in database searches that are much more closely related to the BetP protein from C. glutamicum then those listed in Table 1.

Only two of the functionally characterized transporters of the BCCT-family are physiologically not connected with microbial osmotic adjustment processes: the CaiT proteins from E. coli and Proteus mirabilis (Table 1). The CaiT proteins are unusual members of the BCCT-family, since they do not require a sodium- or proton-gradient to fuel transport and instead function according to the substrate:product antiport principle. L-carnitine (Fig. 2) is taken up in E. coli via CaiT under anaerobic growth conditions when no other electron acceptor or glucose is present and it is then metabolized to $\gamma$-butyrobetaine (Fig. 2) that is subsequently excreted via the CaiT antiporter (Jung et al., 2002). The genetic regulation of the caiTABCDE gene cluster reflects this physiological role. It is controlled by the globally acting regulators CRP and FNR (both positively acting) and the nucleoid-associated protein H-NS (negatively acting) of $E$. coli and by the carnitine-responsive activator protein CaiF 300 (Buchet et al., 1998). A BCCT carrier (DddT) was recently shown to mediate uptake of 301 sulfur-containing compatible solute dimethylsulfoniopropionate (DMSP) (Fig. 2) in a relative of Halomonas venusta (Todd et al., 2010). DMSP is widespread in marine environments and can be used by microorganisms as an effective osmoprotectant or as a versatile sulfur source (Pichereaux et al., 1998; Dickschat et al., 20110; Vila-Costa et al., 2010). DddT-mediated uptake of DMSP in the studies Halomonas strain is connected with catabolism since 
306

307

308

309

310

311

312

313

314

315

316

317

318

319

320

321

322

324

325

326

327

328

329

330

331

332

333

334

335

336

337

338

339

expression of the $d d d T$ gene is induced by DMSP and two of its metabolites (Todd et al., 2010).

The majority (19 out of 22) of the currently functionally characterized BCCT carriers (Table 1) are involved in microbial adjustment to high osmolarity surroundings via uptake of compatible solutes or their biosynthetic precursors. In line with these physiological functions, expression of their structural genes is typically induced in cells grown at high osmolarity. With the exception of the proton-coupled choline transporter BetT from E. coli and from Pseudomonas syringae and CutT from Staphylococcus xylosus (Lamark et al., 1991; Rosenstein et al., 1999; Tondervik and Strom, 2007; Chen and Beattie, 2008), substrate uptake via BCCT carriers is driven by sodium symport (Table 1). As an example, BetPmediated import of one molecule of glycine betaine is accompanied by the uptake of two sodium ions (Farwick et al., 1995; Peter et al., 1996). Since glycine betaine concentration above $1 \mathrm{~mol} / \mathrm{l}$ can be attained by $C$. glutamicum, massive amounts of $\mathrm{Na}^{+}$ions will be pumped into the cell under osmotic stress conditions. It is apparent that the functioning of $\mathrm{Na}^{+}$-driven BCCT carrires for osmoprotectants (Table 1) must be physiologically coupled to the functioning of $\mathrm{Na}^{+}$extrusion systems in order to keep the intracellular concentration of this cytotoxic cation low (Padan et al., 2005).

Functional data, such as $\mathrm{K}_{\mathrm{M}}$ and $\mathrm{V}_{\max }$ values, sodium- or proton-coupling and a description of their activity regulation are available only for a few of the BCCT carriers systems listed in Table 1. We refer the readers for a detailed account of these topics to the original publication (Table 1). A convenient way to assess the substrate specificity of a given BCCT carriers, or the genetic section for BCCT carriers-encoding genes form different microorganisms by functional complementation (Kappes et al., 1996; Peter et al., 1996; Ly et al., 2004), is the use of an E. coli K-12 mutant strain (MKH13), which lacks the genes for choline uptake via BetT and glycine betaine synthesis (betBA) and that is simultaneously defective in the ProU and ProP compatible solute transport systems (Haardt et al., 1995).

It is generally not firmly understood at the molecular level how bacteria sense osmotic stress and how this environmental cue ultimately results in altered gene transcription (Bremer and Krämer, 2000; Cheung et al., 2003; Nagarajavel et al., 2007; Romeo et al., 2007; Rosenthal et al., 2008; Altendorf et al., 2009; Krämer, 2010). Information on osmotically controlled gene expression is available for only a few of the functionally characterized BCCT carriers (Table 1). For instance, osmotic induction of betP transcription is governed by the two-component MtrAB regulatory system of C. glutamicum (Moker et al., 2004; Moker et al., 2007). Expression of the B. subtilis opuD gene is partially dependent on the alternative 
340

341

342

343

344

345

346

347

348

349

350

351

352

353

354

355

356

357

358

359

360

361

362

363

364

365

366

367

368

369

370

371

372

373

transcription factor SigB (F. Spiegelhalter and E. Bremer; unpublished data), the master regulator of the general stress regulon. SigB also controls the osmotic induction of ect $T$ from Virgibacillus pantothenticus (Kuhlmann et al.; unpublished data). The substrates of osmotically induced BCCT carriers typically do not trigger gene expression of their corresponding structural genes, with the exception of the choline transporters BetT from $E$. coli (Lamark et al., 1996) and CudT from Staphylococcus xylosus (Rosenstein et al., 1999) where unrelated choline-responsive repressor proteins (BetI and $\mathrm{CudC}$ ) have been identified. Osmoregulation and simultaneous substrate induction of betT and cudT transcription is of physiological relevance because the function of choline as an osmoprotectant is entirely dependent on its conversion into glycine betaine.

It is increasingly recognized that compatible solutes not only function as microbial osmoprotectants, but serve other stress protective functions as well (Yancey, 2005; Empadinhas and da Costa, 2008). In particular, a compatible-solute-mediated temperature stress protection both at the upper and lower boundaries of growth has been observed in various microbial species. BCCT carriers participate in these processes in several microorganisms. Examples are the BetT-mediated uptake of choline in E. coli (Caldas et al., 1999) and the OpuD-mediated uptake of glycine betaine in B. subtilis as heat stress protectants (Holtmann and Bremer, 2004), the chill stress protection by glycine betaine via BetL-mediated import in Listeria monocytogenes (Angelidis and Smith, 2003; Sheehan et al., 2006) and OpuD in B. subtilis (Hoffmann and Bremer; unpublished data) and the EctTmediated uptake of ectoine/hydroxyectoine in $V$. pantothenticus (Kuhlmann et al.; unpublished data).

\section{The BetP transporter from C. glutamicum and other BCCT carriers: structure, function} and regulation

\section{Function of BetP from $C$. glutamicum in response to osmotic stress}

In comparison to other bacteria such as E. coli (Altendorf et al., 2009) or B. subtilis (Bremer, 2002), which employ a combination of primary transporters (the ABC transporters) and secondary transporters, uptake of compatible solutes in C. glutamicum is mediated entirely by osmoregulated secondary transporters (Peter et al., 1998b). Three of them, BetP, EctP, and LcoP, are members of the BCCT family. These transporters vary in substrate specificity, affinity, and transcriptional regulation, but all respond to hyperosmotic stress by regulating the level of transport activity (Krämer, 2009). BetP is by far the best described, both with respect to transport and regulation. BetP is specific for glycine betaine and couples its uptake 
to the electrochemical $\mathrm{Na}^{+}$potential (smf) by co-transport with two $\mathrm{Na}^{+}$ions, leading to extremely high accumulation ratios up to $10^{6}$ and internal concentrations above $1 \mathrm{~mol} / \mathrm{l}$ (Farwick et al., 1995; Peter et al., 1996).

The activity of BetP is close to zero in the absence of hyperosmotic stress. Upon osmotic challenge, BetP starts taking up betaine in less than a second (Peter et al., 1998a). When transport activity is plotted against the extent of osmotic stress, a steep sigmoidal increase in activity is observed until an optimum is reached; in intact $C$. glutamicum cells this occurs around $1.3 \mathrm{osmol} / \mathrm{kg}$ (Fig. 3). Consequently, besides its catalytic activity $\left(\mathrm{Na}^{+}\right.$-coupled glycine betaine uptake), BetP acts both as an osmosensor and an osmoregulator by responding to osmotic stress with instant regulation of its transport activity. This fact was documented both by heterologous expression of the betP gene in E. coli (Peter et al., 1996), and by reconstitution of the purified BetP protein in proteoliposomes (Rübenhagen et al., 2000). In these two artificial membrane surroundings, the BetP transporter from C. glutamicum retained all its functions, indicating that no other proteinaceous activating factors are involved in controlling BetP activity. The differences in the activation pattern, observed in Fig. 3, can be explained by a significantly different share of negatively charged phospholipids in the membranes of the two different organisms (Schiller et al., 2006).

Activation of BetP is likely modulated through transitions between at least two different functional and conformational states: inactive or active. Hyperosmotic stress will shift the balance towards the active state, while hypo-osmotic stress will favour the inactive conformation of BetP. Thus, the function of BetP can be described by a kinetic scheme (Fig. 4) comprising two functional cycles: (i) The catalytic cycle of glycine betaine transport corresponds to that of a secondary transporter. It includes a conformational change between outward and inward facing carrier molecules (Jardetzky, 1966) and a cycle between substrate binding and release. The turnover in this cycle depends on both glycine betaine availability and the energetic driving force. (ii) The balance between the two-state regulatory cycles of BetP depends on certain stimuli; some of them are related to osmotic stress. An assumption inherent in the regulatory cycle of BetP as depicted in Fig. 4 is that the occluded states of the transporter has been chosen as the points where the two cycles connect, but the mechanistically correct connection point is not known so far. During both the catalytic and the regulatory cycle, BetP passes through several functional states and, consequently, must adopt different conformations. 
408

409

410

411

412

413

414

415

416

417

418

419

420

421

422

423

424

425

426

427

428

429

430

431

432

433

434

435

436

437

438

439

440

441

\section{X-ray structures of BetP and CaiT: structural models for members of the BCCT family} BCCT carriers involved in osmotic stress response catalyze $\mathrm{Na}^{+}-$or $\mathrm{H}^{+}$-symport, during which the smf or pmf drives the conformational change from an outward-facing to an inwardfacing state according to the alternating access mechanism of secondary transporters (Jardetzky, 1966) (Fig. 4). Structural data are required in order to understand the mechanisms of ion-coupled osmolyte symport by BCCT carriers. Crystal structures of two members of this transporter family are available to date: the structure of BetP from C. glutamicum, which was solved by X-ray crystallography to $3.35 \AA$ resolution in complex with its substrate glycine betaine (Ressl et al., 2009) [PDB entry 2WIT], a $3.15 \AA$ structure of CaiT from E. coli in complex with four L-carnitine molecules (Tang et al., 2010) [PDB entry 3HFX], a $3.5 \AA$ structure of CaiT from E. coli in complex with two $\gamma$-butyrobetaine molecules [PDB code: 2WSX] and an apo structure of CaiT [PDB entry 2WSW] from P. mirabilis at $2.3 \AA$ (Schulze et al., 2010). Although CaiT shares the least sequence identity to BetP of all functionally characterized BCCT carriers listed in Table 1, the crystal structures of BetP and CaiT superimpose quite well with an r.m.s.d. deviation of $\sim 2.5 \AA$. Both the purified BetP and CaiT proteins form trimers (Jung et al., 2002; Ziegler et al., 2004; Vinothkumar et al., 2006) and both proteins also crystallize as trimers (Fig. 5). Each subunit consisting of twelve TM $\alpha$ helices and contain a curved amphipathic $\alpha$-helix (helix 7) that runs parallel to the plane of the cytoplasmic membrane and a long bend TM helix (TM2), which both provide a hydrophobic scaffold surrounding the centre of the transporter (Fig. 6). Helix 7 is located at the trimer centre of both the BetP and CaiT transporters, close to the periplasmic membrane surface, where it mediates contacts between all three subunits within the trimer at the periplasmic side.

A feature that distinguishes BetP from CaiT is a $\alpha$-helical $\mathrm{C}$-terminal domain protruding into the cytoplasm (Fig. 5B). In BetP, the C-terminal domain on the cytoplasmic side contributes to trimer contacts and as a result, a slightly different subunit arrangement within the trimers of the BetP and CaiT crystal structures are observed (Fig. 5B). In comparison to BetP, each subunit within the trimer assembly is tilted somewhat resulting in a larger cavity in the trimer centre of CaiT (Fig. 5B, black arrow). TM3, TM4, TM8 and TM9 form an iris-shaped 4-helix bundle close to the centre of both the BetP and CaiT subunit, with aromatic side chains in TM4 and TM8 contributing to the substrate-binding site (Fig. 7B).

The $3.15 \AA$ crystal structure of CaiT from E. coli reveals four L-carnitine molecules (Fig. 7A) most likely because the protein was crystallized with an excess of L-carnitine. The primary binding site at the center of the protein and the secondary substrate-binding site at the bottom of the intracellular vestibule have been confirmed by site-directed mutagenesis studies 
(Tang et al., 2010), while the two others L-carnitine molecules might by associated with the crystallized CaiT protein for structural reasons. The ligand-binding site in one of the E. coli CaiT structure contains a bound $\gamma$-butyrobetaine (Schulze et al., 20210), the substrate that is exported from the $E$. coli cell after metabolism of L-carnitine under anerobic growth conditions (Eichler et al., 1994; Jung et al., 2002). As observed in the CaiT structure in complex with L-carnitine, the bulky headgroup of $\gamma$-butyrobetaine is coordinated by cation-pi interactions and van-der-Waals contacts. In contrast, the central binding site of the $P$. mirabilis CaiT structure does not contain any bound substrate. A second $\gamma$-butyrobetaine molecule is bound in the extracellular cavity of the E. coli CaiT protein (Fig. 7A). Instead of $\gamma$-butyrobetaine, two ordered water molecules occupy the corresponding position in the $P$. mirabilis CaiT protein, most likely because access of the substrate is blocked by crystal contacts. The functional role of this putative second ligand-binding site is unclear. The different CaiT crystal structures revealed that two of the L-carnitine binding sites are identical to those containing $\gamma$-butyrobetaine, while the other two L-carnitine sites most likely contain non-specifically bound substrate (Tang et al., 2010; Schulze et al., 2010).

The central binding site (Fig. 7B) of L-carnitine and $\gamma$-butyrobetaine in CaiT correspond to the glycine betaine-binding site present in BetP (Ressl et al., 2009). However, the bound L-carnitine and $\gamma$-butyrobetaine molecules in the CaiT structures are accessible from the cytoplasm, while in the BetP structure, the access to the bound glycine betaine molecule is occluded from both sides of the membrane (Fig. 7C). In TM4 and TM8 of BCCT carriers, highly conserved aromatic residues, including those that are part of the BCCT signature sequence (Kappes et al., 1996; Saier, 2000), stabilize the 4 TM helix bundle in the CaiT and BetP subunits. The amino acid sequence of TM3 in the BetP and CaiT proteins is not conserved; however, both crystal structures revealed that this trans-membrane region has a locally unwound segment approximately halfway across the membrane (Fig. 7A). In BetP, TM3 harbours one of the $\mathrm{Na}^{+}$ion binding sites. This sodium ion contributes to the coordination of the carboxyl group of glycine betaine (Fig. 2) and, thereby, stabilizes the ligand within in its binding site (Ressl et al., 2009), while the second sodium ion stabilizes the unwound segment of TM3. Unlike BetP, CaiT is a $\mathrm{Na}^{+}$-independent transporter and the functional role of the locally unwound segment in TM3 is therefore not immediately obvious. However, two residues present in TM3 of CaiT are involved in interactions with the Lcarnitine molecule trapped in both the primary and secondary binding site. Interestingly, an Arg residue in TM7 in CaiT occupies the position of the second $\mathrm{Na}^{+}$-binding site present in BetP. Similar to $\mathrm{Na}^{+}$, the positive charge of the Arg amino acid side chain stabilizes the 
476

477

478

479

480

481

482

483

484

485

486

487

488

489

490

491

492

493

494

495

496

497

498

499

500

501

502

503

504

505

506

507

508

509

unwound helix in TM3. The coordination of the carboxyl group of the $\gamma$-butyrobetaine ligand is maintained in CaiT by the sulfur of a Met residue that is highly conserved in CaiT-related proteins but it is absent in BetP-related proteins.

The crystal structures of BetP (Ressl et al., 2009) and of CaiT (Tang et al., 20210: Schulze et al., 2010) share a strikingly similar architecture with that of other $\mathrm{Na}^{+}$-coupled symporters like LeuT (Yamashita et al., 2005; Singh et al., 2007; Zhou, 2007; Singh et al., 2008), vSglT (Faham, 2008) and Mhp1 (Weyand, 2008), with $\mathrm{H}^{+}$-coupled symporters like ApcT (Shaffer et al., 2009) and antiporters like AdiC (Gao et al., 2010), despite the fact that they are not related at the amino acid sequence level. Each of these transporters possesses a core domain consisting of $10 \mathrm{TM}$ helices. Hydropathy profile alignments (Lolkema and Slotboom, 2008) confirm the structural similarity between transporters of the neurotransmitter:sodium:symporter family (LeuT), the sodium:solute:symporter family (vSglT), and the aminoacid:polyamine:organocation family (ApcT) (Gouaux, 2009; Krishnamurthy et al., 2009; Shaffer et al., 2009). These ten C-terminal TMs (corresponding to TM3-12 in BetP) contain an inverted repeat of two 5 TM helixes each. Repeat 1 (TM3TM7 in BetP) is a structural homolog of repeat 2 and they are related by pseudo two-fold symmetry axis running parallel to the membrane (Fig. 6B). Substrate and co-substrate binding sites are all located in the interface between the two intertwined repeats. A superposition of the core structures of this group of transporters reveals an r.m.s.d. of 3.8-4.5 $\AA$, indicating not only a high degree of structural conservation with respect to the overall fold but also to the position of the substrate and co-substrate binding sites (Caplan et al., 2008; Noskov and Roux, 2008; Ressl et al., 2009). The common core structure, the similar location of the substrates in these transporters, and the fact that the crystal structures reflect distinct conformations, were recently used to propose a common molecular mechanism for $\mathrm{Na}^{+}$- and $\mathrm{H}^{+}$-coupled symport and antiport (Abramson and Wright, 2009; Gouaux, 2009; Krishnamurthy et al., 2009; Shaffer et al., 2009).

The $\mathrm{Na}^{+}$-coupled glycine betaine symporter BetP and the L-carnitine/ $\gamma$-butyrobetaine antiporter CaiT represent different subgroups within the BCCT carriers (Table 1). However, the striking similarities of their crystal structures provide now a solid basis for formulating unifying concepts that describe functional mechanisms operating within the BCCT family. In our comparisons of a large number of BCCT carriers, we noted a high amino acid sequence conservation of those residues that are involved in coupling and substrate binding within the BCCT family. The degree of sequence identity in TM3, TM4 and TM8 is very high within the BCCT family. However, there are two distinct pattern of conservation: (a) residues involved 
510

511

512

513

514

515

516

517

518

519

520

521

522

523

524

525

526

527

528

529

530

531

532

533

534

535

536

537

538

539

540

541

542

543

in ion-coupling or counter-substrate coupling and (b) residues involved in binding of the fully methylated head group of various compatible solutes (Fig. 2 and 7B). Therefore, the structures of BetP and CaiT probably can be used to explain transport of other methylated ammonium or sulfur compounds such as choline and DMSP and permits structure-guided speculations on the transport mechanism of non-quaternary ammonium substrates of BCCT carriers such as ectoine and hydroxyectoine (Fig. 2). Thus, the BetP and CaiT structures allow us to search for key residues that are likely to be involved in functionally relevant conformational changes in BCCT carriers.

\section{Substrate binding: what determines substrate specificity and coupling mode in the} BCCT family?

In general, it is not possible to predict with confidence the substrate profile of a given BCCT carrier solely by inspecting and aligning amino acid sequences. However, the BetP and CaiT structures reveal a striking pattern in substrate binding that allows one, at least to some extent, to predict the substrate profile of other BCCT carriers based on sequence alignments. Glycine betaine transporters of the BCCT family show a substantial degree of sequence relatedness (between 48-40\%) in the $10 \mathrm{TM}$ transporter core (excluding the N-terminal and C-terminal extensions). In contrast, the amino acid sequence relatedness of the $10 \mathrm{TM}$ core falls below $40 \%$ for ectoine and choline transporters and even lower (below $30 \%$ ) for L-carnitine $/ \gamma$ butyrobetaine antiporters.

The BetP crystal structure revealed the architecture of the binding site for its ligand glycine betaine and the functional importance of key-residues within this binding site were confirmed by site-directed mutagenesis studies (Ressl et al., 2009). The architecture of the ligand-binding site present in BetP is nearly identical with the primary ligand-binding site for L-carnitine and $\gamma$-butyrobetaine in CaiT (Tang et al., 20210; Schulze et al., 2010). Hence, the crystal structures of BetP and CaiT revealed for the first time the molecular determinants for substrate binding of trimethylammonium compounds by members of the BCCT carriers. In particular, the indole groups of three tryptophane residues, one positioned in TM4 and two positioned in TM8, are arranged in form of an aromatic cage in which the fully methylated head groups of glycine betaine, L-carnitine and $\gamma$-butyrobetaine (Fig. 2) are stabilized via cation-pi interactions. The carboxyl groups of these ligands protrude out from this aromatic cage and are coordinated via hydrogen bonding interactions within the ligand-binding site (Fig. 7B). The coordination of the glycine betaine, L-carnitine and $\gamma$-butyrobetaine substrates within the BetP and CaiT transporters show striking similarities to that found in the ligand- 
544 binding proteins (ProX) of the glycine betaine ABC-type uptake system from E. coli 545 (Schiefner et al., 2004a) and the hyperthermophilic archaeon Archeoglobus fulgidus 546 (Schiefner et al., 2004b). The ProX proteins are soluble and function in the context of ABC547 transporters and are thus not evolutionarily closely related to the integral membrane proteins 548 BetP and CaiT. Hence, nature has used common design principles to achieve the selective and 549 high-affinity binding of this group of compatible solutes by proteins, compounds which are 550 typically preferentially excluded from the hydration shell of the protein backbone (Arakawa 551 and Timasheff, 1985; Bolen and Baskakov, 2001; Street et al., 2006; Rosgen, 2007; Bolen 552 and Rose, 2008; Street et al., 2010). The crystal structures of ligand-binding proteins from 553 ABC- and TRAP-transport systems revealed that the binding of compatible solutes in substrate-selective binding sites present in transporter proteins seems to require a certain number of aromatic residues for substrate coordination via cation-pi and van der Waals interactions in order to provide a surface that minimally repels osmolytes (Schiefner et al., 2004a; Horn et al., 2006; Hanekop et al., 2007; Kuhlmann et al., 2008; Smits et al., 2008; Capp et al., 2009; Lercher et al., 2009; Ressl et al., 2009; Tang et al., 20210; Schulze et al., 20210; Wolters et al., 2010). Several crystal structures of binding proteins from ABC- or TRAP-type transport systems in complex with compatible solutes used by BCCT carriers (Table 1) have been reported (Schiefner et al., 2004a; Schiefner et al., 2004b; Horn et al., 2006; Hanekop et al., 2007; Kuhlmann et al., 2008; Oswald et al., 2008; Smits et al., 2008; Lecher et al., 2009; Wolters et al., 2010). Hence, the coordination of the substrates in these soluble proteins might give valuable clues to substrate binding site(s) present in BCCT carriers for which no crystal structure is yet available (e.g. transporters for ectoines and DMSP).

Most of the BCCT carriers show a high degree of conservation of the Trp residues in TM4 and TM8 that coordinate the trimethlyammonium ligands in BetP and CaiT (Ressl et al., 2009: Tang et al., 2010; Schulze et al. 20210) but these residues can not be identified in ectoine/hydroxyectoine transporters of the BCCT-family. From these patterns of conservation, we conclude that the coordination of ectoine or hydroxyectoine, which lack a quaternary ammonium group (Fig. 2), is different from that of glycine betaine, $\gamma$ butyrobetaine or L-carnitine, while coordination of choline is likely to be similar. This latter suggestion is supported by the molecular determinants governing choline binding by the periplasmic ligand binding ChoX protein from Sinorhizobium meliloti that also archives the binding of the methylated head group of choline through cation-pi interactions in an aromatic ligand-binding cage (Oswald et al., 2008). 
Like glycine betaine, ectoine and hydroxyectoine carry a negatively charged carboxylate (Fig. 2). Hence, it is tempting to speculate that a sodium ion might interact directly with the carboxylate of ectoine and hydroxyectoine in a similar way to that found in BetP (Ressl et al., 2009). The coordinating $\mathrm{Na}^{+}$ion in the BetP crystal structure is located halfway across TM3, close to an unwound, glycine-rich segment that separates TM3 into two segments (Fig. 7B). This flexible segment in BetP contains a GMGIG motif that is conserved in glycine betaine-specific transporters of the BCCT family. TM3 in the $\mathrm{Na}^{+}$-independent substrate:product antiporter CaiT shows now sequence homology in this region, while ectoine-specific BCCT carriers show sequence modifications at the corresponding position. Substrate-coordination by residues in TM3 might also be crucial for proton-coupled BetT-like proteins of the BCCT family. The chemical nature of glycine betaine and choline differs with respect to their carboxyl and alcohol groups (Fig. 2). While salt bridges to the substrate are maintained in $\mathrm{Na}^{+}$-coupled transporters by the coupling ion, this might not be the case for choline, which carries a positive charge (Fig. 2). However, the choline transporter BetT from E. coli comprises a charged residue in the flexible segment in TM3. The presence of a side chain capable of reversible protonation during the transport cycle might be a pre-requisite for the $\mathrm{H}^{+}$-coupled transport, since such an arrangement was also observed in the $\mathrm{H}^{+}$-coupled amino acid transporter ApcT from Methanocaldococcus jannaschii (Shaffer et al., 2009).

There might be substrates for BCCT carriers that are different from those compiled in Fig. 2. Some putative BCCT carriers harbour conserved, but significant different motifs of the glycine betaine, choline, ectoine or carnitine transporters of the BCCT-family. This functionally uncharacterized group of BCCT carriers is predominantly found in members of the Firmicutes, and they also form the major group of BCCT carriers present in Synechococcus, a subclass of cyanobacteria. Depending on the degree of their salt stress resistance these microorganisms synthesize sucrose, trehalose, glucosylglycerol and glycine betaine under salt stress (Hagemann, 2010). Some marine $\gamma$-Proteobacteria possess BCCT carriers with a very low degree of sequence homology to BetP (approximately 20\%) and, most strikingly, they lack TM1. Accordingly, these transporters have a predicted transmembrane topology that is different from that of BetP. These considerations suggests that it might be rewarding to study these so-far uncharacterized BCCT carriers with respect to their potential substrates, their transport activity profiles and topological organization within 


\section{The oligomeric state of BCCT carriers and their terminal domains}

613 BetP and CaiT are both trimeric in detergent solution (Ziegler et al., 2004; Vinothkumar et $614 a l ., 2006)$, as well as in the membrane when analyzed by 2D electron crystallography, and in 615 the 3D crystal (Ressl et al., 2009; Tang et al. 2010; Schulze et al., 2010; Tsai et al., 616 submitted). The observed trimer formation is a consequence of the unique structural elements 617 characterizing the fold of the BCCT carriers, which are the amphiphatic helix 7 and the long 618 bend TM2. They provide a hydrophobic interface, which force a triangular subunit 619 arrangement for stability reasons. In fact, BetP and CaiT have proven to be very stable both in 620 detergent solution and when reconstituted back into the membrane (Tsai et al. 2007). It is thus tempting to speculate that trimer-formation is a general feature of the BCCT carriers with functional impact for transport and/or regulation. We have analyzed the differences in trimer contacts in the osmotically regulated BetP and the osmotically non-regulated CaiT proteins to validate this assumption. The three subunits within the CaiT and BetP trimer form a central conical cavity lined by aromatic side chains from TM2, TM3 and h7 (Fig. 5A). The hydrophobic cavity in the trimer centre is most likely filled with lipid as observed for the crystallized BetP protein (Ressl et al., 2009). Residues contributing to the formation of this cavity are highly conserved in members of the BCCT carriers. On the periplasmic side, the amphipathic helix 7 is the key player in maintaining trimer contacts (Fig. 6). Helix h7 in BetP and CaiT is rich in Leu and Asp residues and shows characteristics of a non-specific lipid interaction site that stabilizes the trimer assembly. This helix represents a structurally distinct feature of the BCCT carriers since it is not present in any other transporter sharing the same overall inverted structural repeat (e.g. LeuT). In BetP and CaiT, helix h7 separates the two structural repeats from each other and, therefore, cannot be attributed to either of the repeat parts of the transpiorter proteins. Contacts involve mainly hydrophobic residues in helix h7, TM2, TM3 and loop7 of adjacent subunits. Residues participating in trimer contact via helix

$637 \mathrm{~h} 7$ are not entirely conserved within the BCCT carriers. CaiT shares only $17 \%$ sequence 638 identity in this region to the BetP protein. However, the two structurally important polar 639 interactions observed in BetP are also found in CaiT and are predicted to occur in eight other 640 BCCT carriers listed in Table 1. In CaiT and nine other BCCT carriers, additional subunit641 subunit contacts are likely to be promoted by ionic interactions, resulting in a quite rigid 642 trimer assembly; in contrast, in BetP they are formed by more flexible hydrophobic 643 interactions. However, only $\mathrm{BetP}_{\mathrm{Cg}}$ and $\mathrm{OpuD}_{\mathrm{V}_{\mathrm{c}}}$ (Table 1) seem to have exclusively 644 hydrophobic interactions in their trimer contact regions as found in BetP. The majority of 645 BCCT carriers show (i) a conserved length of $\mathrm{h} 7$ and (ii) the potential for both hydrophobic 
646 and ionic interactions via helix h7. Both parameters favour a triangular interface, while a 647 dimer or a tetramer formation is not possible. Therefore we can safely assume that the 648 majority of BCCT carriers form trimers in the plane of the cytoplasmic membrane. It seems 649 that BetP and CaiT represent two different structural solutions within the BCCT carriers to 650 foster trimerization.

651 It is an intriguing question whether the flexible trimer interactions observed in BetP in 652 comparison to those found in CaiT can be related to BetPs osmoregulatory abilities. Subunit 653 interactions within the BetP trimer not only involve helix $\mathrm{h} 7 \mathrm{but}$ also involve the C-terminal 654 helix of each BetP subunit within the trimer assembly; this C-terminal extension interacts 655 with loop 2 and the C-termini of the other two BetP subunits. Only when the subunits are 656 arranged in a trimer, individual C-terminal domains of BetP would not hinder each other sterically. The C-terminal helix of BetP is not found in CaiT (Fig. 5). Th additional trimer 658 contact formed by the C-terminal helix of BetP within the BetP trimeric structure is of 659 particular interest because biochemical studies have provided compelling evidence for the 660 involvement of this domain in osmosensing and regulation (Ott et al., 2008). The C-terminal 661 domain of BetP contains several positively charged residues clustered at the N-terminal part 662 of the C-terminal domain (cluster 1: R554, R558, R565, R567, and R568) and near the end of 663 the C-terminal domain (cluster 2: R576, K581, R582-584, R586, and K587). It lacks Gly 664 and/or Pro residues, except close to its very end, and thus forms a straight $\alpha$-helix (Fig. 5B and $6 \mathrm{~B})$. Biochemical data revealed the functional importance of the conformation and position of the first charge cluster within the C-terminal domain of BetP (Ott et al., 2008;

667 Ressl et al., 2009). In the context of trimer contacts in BetP, arginines in the first cluster form salt bridges to a glutamate separating both clusters in the C-terminal domain of the adjacent subunit. In the 22 functionally characterized microbial BCCT carriers (Table 1), the C-

670 terminal domains do not have a conserved sequence, but three different motifs can be 671 observed: (i) BetP-type C-terminal domains feature two clusters with opposite charges 672 positioned several residues apart from each other, but lack flexible stretches of Gly and/or Pro 673 residues. (ii) CaiT-type C-terminal domains have, at most, very short charged clusters. 674 Consequently, the BetP-type C-terminal domains present in $\mathrm{BetP}_{\mathrm{Cg}}$, BetT $\mathrm{Ah}_{\mathrm{Ah}}$ CudT, BetH $\mathrm{Ht}_{\mathrm{H}}$, $675 \mathrm{OpuD}_{\mathrm{Bs}}$, EctM, ButA and EctP (Table 1) are likely to contribute to trimer contacts, while 676 CaiT-type C-terminal domains present in BetM and DddT (Table 1), do not do so. (iii) There 677 is a third type of C-terminal domain in members of the BCCT carriers. It consists of charged 678 clusters but is also rich in Gly and/or Pro residues, suggesting that these C-terminal domains 679 are not entirely $\alpha$-helical. This type of C-terminal domain is often very long (> 70 aa) and is 
680 found in the Bet $\mathrm{T}_{\mathrm{Ec}}$, Bet $\mathrm{T}_{\mathrm{Ps}}$, BetP $\mathrm{Hi}_{\mathrm{Hi}}$, BetS and BetU transporters (Table 1). For several 681 members of the BCCT carriers, namely BetL, BetP $\mathrm{Vp}_{\mathrm{p}}, \mathrm{OpuD}_{\mathrm{Vc}}$, and LcoP (Table 1), the 682 assignment to the three types of C-terminal domains is not a trivial task, since they all 683 comprise charged amino acid clusters together with flexible stretches of glycine and/or

684

685

686

687

688

689

690

691

692

693

694

695

696

697

698

699

700

701

702

703

704

705

706

707

708

709

710

711

712

proline residues. A BetP-like helix h7 and a BetP-like C-terminal domain are found together only in the glycine betaine transporter ButA from Tetragenococcus halophila (Table 1) (Baliarda et al., 2003).

Interactions of C-terminal domains with the cytoplasmic side of adjacent subunits are one of the main differences between the BetP (Ressl et al., 2008) and the CaiT structures (Tang et al., 2010; Schulze et al., 2010). The C-terminal interactions are not symmetrical in the BetP trimer resulting in a break in non-crystallographic threefold symmetry. A break in symmetry was also observed for BetP embedded in the membrane in 2D crystals (Ziegler et al., 2004), while the CaiT trimer exhibits a perfect threefold symmetry. Unfortunately, electron crystallographic data of CaiT are not available yet at the required resolution, but with respect to trimer formation it is very likely that CaiT is also a symmetric trimer in the membrane. In contrast, each subunit in the BetP trimer adopts a distinct conformation (Tsai et al., submitted). The different conformations of each subunit in membrane-embedded BetP, the structural flexibility of the C-terminal domains and of the BetP trimer suggest a role of trimerization far beyond protein stabilization in BetP. Together with the fact the C-terminal domains acts as osmoregulator, the observed C-terminal interactions point towards a functional role in transport activity regulation in BetP (Krämer, 2009). A possible scenario would be that the subunits communicate their conformational state via the trimer interface to synchronize their transport activity. Thereby, the BetP glycine betaine transporter would take advantage of the trimeric state in a very elegant fashion.

\section{Sensing and signal transduction by BetP at the biochemical level}

A considerable number of the BCCT carriers listed in Table 1 respond to osmotic stress but this issue has only been studies in detail for a few of threes transporters. In view of the multiplicity of potential physical stimuli directly or indirectly related to osmotic stress (Wood, 1999; Bremer and Krämer, 2000; Poolman et al., 2004; Wood, 2006; Krämer, 2009; Altendorf et al., 2009), the analysis of the sensory input into a transporter protein is an experimentally difficult task. For BetP, the situation was simplified by the fact that the reconstituted protein in proteoliposomes was fully capable of responding to osmotic stress 
713 (Rübenhagen et al., 2000). Consequently, individual physical stimuli could be tested 714 separately and their relevance for carrier activation could be carefully evaluated.

The physical stimuli found to be relevant for the osmotic control of BetP activity can been divided into two classes: (i) An increase in $\mathrm{K}^{+}$(and $\mathrm{Rb}^{+}$or $\mathrm{Cs}^{+}$) triggers BetP activity but only when applied at the cytoplasmic side (Rübenhagen et al., 2001). The observed specificity with respect to the activating agent practically excludes the unspecific effect of a change in the degree of BetP hydration as a stimulus. An unspecific influence of osmolytes and macromolecules has been proposed as a stimulus for osmotic control of the MFS-type transporter ProP from E. coli (Culham et al., 2003). (ii) BetP activity is also affected by stimuli originating from the membrane. A modulating effect of local anaesthetics inserted into the membrane affects BetP-mediated glycine betaine transport (Steger et al., 2004). This is not an unspecific effect, since these types of compounds did not affect the BCCT carrier EctP from $C$. glutamicum. It was also observed that the surface charge density of the surrounding membrane strongly modulates BetP activity; the concentration of $\mathrm{K}^{+}$necessary for BetP activation increased in parallel to the content of negatively charged lipids (Schiller et al., 2006). In addition to osmotic stress, BetP was also activated by chill stress (Özcan et al., 2005). Since this effect was independent of changes in $\mathrm{K}^{+}$content the relevant stimulus should originate from changes in the physical state of the membrane. Finally, membranes with changed lipid composition but unchanged surface charge density exhibit altered regulation of the BetP transporter (Özcan et al., 2007). Taken together, signal input leading to stimulation of BetP transporter activity seems to be of two types: a rise in the intracellular $\mathrm{K}^{+}$ concentration that follows an osmotic up-shift and a stimulus originating from the membrane into which the BetP transporter is embedded.

Mutational studies of BetP have provided substantial information on the contribution of selected domains with respect to its transport function and regulation of its activity by high osmolarity. A stepwise truncation of the C-terminal domain of BetP showed that the Cterminal region containing the second charge cluster could be deleted without significant impact on transporter function. Further truncation of the C-terminal domain by 25 amino acid residues or more, including the first charge cluster, led to BetP transporter derivatives with decreased but constitutive activity (Peter et al., 1998a; Schiller et al., 2004). Full removal of the C-terminal domain rendered BetP inactive. Interestingly, activation of BetP activity at low

744 temperature, probably by a stimulus derived from the surrounding membrane, was not 745 influenced by a truncation of the C-terminal domain (Özcan et al., 2005). The functional significance of the C-terminal domain of BetP was further studied by amino acid scanning 
747

748

749

750

751

752

753

754

755

756

757

758

759

760

761

762

763

764

765

766

767

768

769

770

771

772

773

774

775

776

777

778

779

mutagenesis (amino acid replacements with Ala or Pro residues) (Ott et al., 2008). These experiments led to two important conclusions: (i) a particular region in the middle of the Cterminal domain of BetP was found to be critical for sensory function with respect to its conformational properties rather than its charge distribution, and (ii) interaction of the Cterminal domain with particular loops at the cytoplasmic face of BetP and with the N-terminal domain was detected (Ott et al., 2008). Consequently, both terminal domains, and in particular the C-terminus, are critically involved in the activation of BetP by osmotic stress. BetT-like choline transporter proteins have C-terminal domains that are substantially longer then that present in BetP (Table 1). In both E. coli and P. syringae, BetT proteins with truncated C-terminal domains gradually lose their capacity for osmotic activation, indicating that these domains are involved in osmosensing and/or osmoregulation of transporter activity (Tondervik and Strom, 2007; Chen and Beattie, 2008).

\section{Sensing and signal transduction by BetP: correlation of structure with function}

Biochemical data elucidated three key players for sensing and signal transduction by BetP: (i) the C-terminal domain, (ii) cytoplasmic loops, and (iii) the N-terminal domain (Fig. 8). While the N-terminal domain is not resolved in the X-ray structure of BetP (Ressl et al., 2009), biochemical data concerning the functional impact of cytoplasmic loops, especially of loop 2 and loop 8, and of the C-terminal domain on osmotic activation and transporter function can be correlated to the BetP crystal structure. Loop 2 preceding TM3 contains a cluster of negatively charged residues (Asp-131, Glu-132 and Glu-135). Mutations at Asp-131 and Glu132 somehow prevent expression of the betP structural gene and a mutation at Glu-135 reduces transport activity (Ott et al., 2008). The BetP structure reveals an interaction of Asp131 via a salt bridge with an Arg residue located in the C-terminal helix of the adjacent subunit, and Glu-132 with an Arg residue in loop 8, which connects TM8 and TM9 and is part of the signature sequence of the BCCT family (Kappes et al., 1996; Saier, 2000). Within this network, changes in orientation of the C-terminal helix in one subunit of BetP would affect the orientation and conformation of loop 2 and loop 8 in an adjacent subunit. It seems likely that such interactions would have consequences for structural features of TM3 and TM8, both of which are involved in substrate binding and $\mathrm{Na}^{+}$coupling. Thus, the structure of BetP suggests a "locking" interaction of the C-terminal domain with these loops, which might translate into an inhibition of transport activity and, consequently, seems to be partly responsible for regulating the transport cycle of BetP. 
Based on biochemical data, activation of BetP by a rise in the internal $\mathrm{K}^{+}$ concentration occurs due to $\mathrm{K}^{+}$binding to the BetP protein at the cytoplasmic site, a fact that has so far not been confirmed by structural data. Presumably, $\mathrm{K}^{+}$binding influences the interaction network of the C-terminal domain with the intracellular loops 2 and 8 . Furthermore, it is reasonable to assume a direct interaction of positively charged residues in the C-terminal domain with negatively charged lipids of the membrane. Lipids occupying the clefts between the individual BetP subunits or in the hydrophobic cavity in the centre of the trimer (Fig. 5) might affect the orientation of the C-terminal helices of BetP, which, in turn, might render a regulatory $\mathrm{K}^{+}$-binding site more accessible. One can further assume that the flexible trimeric state of the transporter may be a crucial point for the activity regulation of BetP. This would involve in all likelihood the amphipathic helix $\mathrm{h} 7$ on the periplasmic side of BetP, a structure that is buried in the membrane interface (Fig. 6). A regulatory mechanism that senses differences in membrane composition or membrane state at the periplasmic side via helix $\mathrm{h} 7$ would be in agreement with a physical stimulus for BetP activity originating from within the membrane. Stimulus perception by helix h7 could be structurally translated into the flexible trimer by rearrangement of the BetP subunits.

The question of which transporters might form additional trimer contacts by their Cterminal domains is of interest within the context of the regulatory properties of BCCT carrier. Furthermore, it is of interest whether the C-terminal interaction with loop 2 and 8, as observed biochemically (Ott et al., 2008) and structurally (Ressl et al., 2009) in BetP, is also found in other members of the BCCT carriers. Loop 8 is nearly $100 \%$ conserved in the BCCT carriers but this is not the case for loop 2. However, six BCCT carriers (Table 1) have a negatively charged cluster at the positions of Asp-131 and Glu-132 and charged cluster in the C-terminal domain at the same position as in BetP. Two additional transporters from $C$. glutamicum, LcoP and EctP, which share with BetP the described profile of charged residues in loop2 and in their C-terminal domain, are indeed both osmoregulated transporters. Lacking glycines and prolines in their C-terminal domains, it can be assumed that these domains are $\alpha$-helical and these transporters might very well be regulated in a similar way as BetP.

Subunit interactions within the trimer seem to be an essential feature of regulation of transport activity in members of the BCCT carriers. This might explain some differences in regulatory behaviour of osmoregulated BCCT carriers such as BetP compared to osmoregulated transporters of other transporter families, e.g. ProP from E. coli (Culham et al.,

812 2008a; Culham et al., 2008b) and OpuA from L. lactis (van der Heide and Poolman, 2000;

813 van der Heide et al., 2001; Mahmood et al., 2009). In fact, this idea has already been 
814 suggested in a previous review (Poolman et al., 2004). However, the concepts derived for the

815 osmotic activity control of transporters involved in compatible solute acquisition must be 816 viewed with caution, since the transporter families, the structure of the OpuA, ProP and BetP 817 transporters and their subunit composition are rather different.

818 Moreover, the putative primary trigger that controls transport activity in response to a 819 high osmolarity challenge seems to be rather different as well: a change in intracellular water 820 availability in the case of ProP (Culham et al., 2003), a change in the intracellular ionic 821 strength for OpuA (van der Heide and Poolman, 2000; van der Heide et al., 2001; Mahmood 822 et al., 2009), and altered cytoplasmic $\mathrm{K}^{+}$concentration in the case of BetP (Rübenhagen et al., 823 2001). Nevertheless, some common features can be deduced from the biochemical analysis 824 the ProP, OpuA and BetP transport systems. Turgor was not found to be responsible for 825 activation of any of these transporters; a switching behaviour of terminal domains as a 826 mechanistic element in regulation has been suggested for all three; and an impact of 827 membrane conditions and composition on carrier activity was found to be relevant for ProP, 828 OpuA and BetP (van der Heide et al., 2001; Poolman et al., 2004; Schiller et al., 2006; 829 Mahmood et al., 2009; Romantsov et al., 2009). It is not possible to generalise, however, on 830 the particular nature of the transport activity-controlling stimulus, the mechanistic details of 831 stimulus sensing, and the concept of how the transport cycle should be connected to the 832 regulatory cycle of the various transporters under study.

\section{The BCCT carriers: conclusions and perspectives}

835 When initially recognized in 1996, the BCCT family of transporters comprised just 4 836 functionally characterized members (Kappes et al., 1996). Since then, the number of 837 functionally studied BCCT carriers has modestly risen to 22 (Table 1). The explosion in the 838 number of available genome sequences of microorganisms revealed a widespread occurrence 839 of BCCT carriers (currently about 2200 representatives) that are predominantly present in 840 members of the Bacteria. Substrates for BCCT carriers different form those originally found 841 (Kappes et al., 1996) have also been detected in the meantime (Fig. 2). Most notably are 842 transporters for ectoines and for DMSP.

BCCT carriers for ectoine and hydroxyectoine (Table 1), widely synthesized as 844 osmostress- and thermostress-protectants by members of the Bacteria (Garcia-Estepa et al., 845 2006; Bursy et al., 2007; Bursy et al., 2008; Kuhlmann et al., unpublished results), are of 846 interest from a crystallographic point of view because the chemical structures of these 847 compatible solutes differ considerably from those of other substrates for BCCT carriers (Fig. 
848 2). Crystal structures of soluble ectoine and hydroxyectoine binding proteins operating in the 849 framework of either ABC- or TRAP-type transporters have recently been determined 850 (Hanekop et al., 2007; Kuhlmann et al., 2008; Lecher et al. 2009). It will be interesting to see 851 if, similar to the situation found for the BetP transporter and the periplasmic binding protein 852 ProX (Ressl et al., 2009; Schiefner et al., 2004a), the ligand-binding site present in 853 ectoine/hydroxyectoine-specific BCCT carriers will correspond to that of the aforementioned 854 soluble ectoine/hydroxyectoine binding proteins.

855 The second type of BCCT carrier that is of considerable physiological interest is that 856 for the compatible solute dimethylsulfoniopropionate (DMSP) (Fig. 2) which is synthesized 857 in huge amounts (about 1 billion tons per year) primarily by marine plankton. It can be used 858 by microorganisms as a sulphur source and can be catabolized to the volatile dimethyl sulfide, 859 a climate-active trace gas (Todd et al., 2010; Dickschat et al., 2010; Vila-Kosta et al., 2010). 860 Since DMSP is also an effective microbial osmoprotectant (Pichereau et al., 1998) it would 861 not be surprising if BCCT carriers for the uptake if DMSP would be discovered in addition to 862 those involved in DMSP uptake (e.g. DddT) for catabolism (Todd et al., 2010).

The crystal structures of $\mathrm{Na}^{+}$-coupled BetP transporter (Ressl et al., 2009) and the substrate:product antiporter CaiT (Tang et al., 2010; Schulze et al., 2010) provided the 865 opportunity to correlate structural features of functionally distinct members of the BCCT 866 family with a wealth of biochemical and physiological data (Jung et al., 2002; Vinothkumar 867 et al., 2006; Schiller et al., 2006; Peter et al., 1998a; Rübenhagen et al., 2001; Ott et al., 868 2008; Krämer, 2009). With respect to BetP, the combination of biochemical and 869 crystallographic analysis provided unprecedented insight into the functioning and activity 870 control of a secondary transporter responsive to osmotic stress. The regulatory response of 871 BetP to increased osmolarity was found to require a partly $\alpha$-helical C-terminal domain of the 872 transporter and, furthermore, evidence has been provided that the trimeric state may be an 873 requirement for functional regulation. Based on the biochemical characteristics and crystal 874 structures of BetP and CaiT, we suggest that many BCCT carriers should form trimeric 875 complexes within the membrane. Our analysis of BetP and CaiT indicates that there might be 876 a relationship between the flexibility of the BetP-type trimer and the osmotic regulation of 877 transport activity and the rigidity of the CaiT-type trimer that is not able to regulate transport 878 activity in response to osmotic challenges. However, we note that structural determinants of 879 trimerization apparently show significant variation with the BCCT carriers. A combination of 880 X-ray crystallography and biochemical analysis will be required to further unravel substrate 
881 binding, transport mechanism and activity regulation of additional members of the BCCT882 carriers in response to environmental stimuli.

883 From a crystallographic and mechanistic point of view, a high-resolution crystal 884 structure of an $\mathrm{H}^{+}$-coupled BetT-type choline transporter (Table 1) would be highly desirable. 885 With the advent of such a structure, a reference protein for each of the three types of 886 transporters grouped together into the BCCT-family (Saier, 2000; Saier et al., 2009) would be 887 available.

888

889 Acknowledgements

890 Work in the author's laboratories on bacterial osmoregulation and the biochemical and 891 structural analysis of BCCT carriers was funded by grants from the Deutsche 892 Forschungsgemeinschaft (DFG), the Max-Planck Society, the Fonds der Chemischen 893 Industrie and the LOEWE program of the State of Hessen (SynMicro LOEWE Centre; 894 Marburg). We are grateful to Vickie Koogle for her kind help in editing of the manuscript. 895 We apologize to all our colleagues whose important work on microbial osmoadaptation and 896 compatible solute transporters could not be appropriately cited due to space limitations.

897

898

899

900

References

901 Abramson, J. and Wright, E. M. (2009) Structure and function of $\mathrm{Na}^{+}$-symporters with 902 inverted repeats. Curr Opin Struc Biol 19: 425-432.

903

Altendorf, K., Booth, I. R., Gralla, J., Greie, J.-C., Rosenthal, A. Z. and Wood, J. M. (2009)

904 Chapter 5.4.5, Osmotic Stress. In: EcoSal-Escherichia coli and Salmonella: cellular and molecular biology. A. Böck et. al. (eds). Washington: ASM Press.

906

Angelidis, A. S. and Smith, G. M. (2003) Role of the glycine betaine and carnitine 907 transporters in adaptation of Listeria monocytogenes to chill stress in defined medium. Appl Environ Microbiol 69: 7492-7498.

Anishkin, A. and Sukharev, S. (2009) State-stabilizing interactions in bacterial mechanosensitive channel gating and adaptation. J Biol Chem 284: 19153-19157.

Arakawa, T. and Timasheff, S. N., (1985) The stabilization of proteins by osmolytes. Biochem J 47: 411-414. 
913

914

915

916

917

918

919

920

921

922

923

924

925

926

927

928

929

930

931

932

933

934

935

936

937

938

939

940

941

942

943

944

945

Auton, M., Bolen, W.D. and Rösgen, J. (2008) Structural thermodynamics of protein preferential solvation: osmolyte solvation of proteins, aminoacids, and peptides. Proteins 73: 802-813.

Baliarda, A., Robert, H., Jebbar, M., Blanco, C. and Le Marrec, C. (2003) Isolation and characterization of ButA, a secondary glycine betaine transport system operating in Tetragenococcus halophila. Curr Microbiol 47: 347-351.

Bolen, D. W. and Baskakov, I. V. (2001) The osmophobic effect: natural selection of a thermodynamic force in protein folding. J Mol Biol 310: 955-963.

Bolen, D. W. and Rose, G. D. (2008) Structure and energetics of the hydrogen-bonded backbone in protein folding. Annu Rev Biochem 77: 339-362.

Booth, I. R., Edwards, M. D., Black, S., Schumann, U. and Miller, S. (2007) Mechanosensitive channels in bacteria: signs of closure? Nat Rev Microbiol 5: 431440.

Bremer, E. (2002) Adaptation to changing osmolarity. In: Bacillus subtilis and its closest relatives: from genes to cells. A. L. Sonenshein, J. A. Hoch \& R. Losick (eds). Washington: ASM Press, pp. 385-391.

Bremer, E. and Krämer, R. (2000) Coping with osmotic challenges: osmoregulation through accumulation and release of compatible solutes. In: Bacterial Stress Responses. G. Storz \& R. Hengge-Aronis (eds). ASM Press, pp. 79-97.

Buchet, A., Eichler, K. and Mandrand-Berthelot, M. A. (1998) Regulation of the carnitine pathway in Escherichia coli: investigation of the cai-fix divergent promoter region. $J$ Bacteriol 180: 2599-2608.

Burg, M. B. and Ferraris, J. D. (2008) Intracellular organic osmolytes: function and regulation. J Biol Chem 283: 7309-7313.

Bursy, J. Pierik, A. J., Pica, N. and Bremer, E. (2007) Osmotically induced synthesis of the compatible solute hydroxyectoine is mediated by an evolutionarily conserved ectoine hydroxylase. J Biol Chem 282: 31147-31155.

Bursy, J., Kuhlmann, A. U., Pittelkow, M., Hartmann, H., Jebbar, M., Pierik, A.J. and Bremer, E. (2008) Synthesis and uptake of the compatible solutes ectoine and 5hydroxyectoine by Streptomyces coelicolor A3(2) in response to salt and heat stress. Appl Environ Microbiol 74: 7286-7296.

Caldas, T., Demont-Caulet, N., Ghazi, A. and Richarme, G. (1999) Thermoprotection by glycine betaine and choline. Microbiology 145 2543-2548. 
946

947

948

949

950

951

952

953

954

955

956

957

958

959

960

961

962

963

964

965

966

967

968

969

970

971

972

973

974

975

976

977

978

979

Caplan, D. A., Subbotina, J. O. and Noskov, S. Y., (2008) Molecular mechanism of ion-ion and ion-substrate coupling in the $\mathrm{Na}^{+}$-dependent leucine transporter LeuT. Biophys $J$ 95: 4613-4621.

Capp, M. W., Pegram, L. M., Saecker, R. M., Kratz, M., Riccardi, D., Wendorff, T., Cannon, J. G. and Record, M. T., Jr. (2009) Interactions of the osmolyte glycine betaine with molecular surfaces in water: thermodynamics, structural interpretation, and prediction of m-values. Biochemistry 48: 10372-103729.

Cayley, S. and Record, M. T., Jr. (2003) Roles of cytoplasmic osmolytes, water, and crowding in the response of Escherichia coli to osmotic stress: biophysical basis of osmoprotection by glycine betaine. Biochemistry 42: 12596-12609.

Chen, C. and Beattie, G. A. (2008) Pseudomonas syringae BetT is a low-affinity choline transporter that is responsible for superior osmoprotection by choline over glycine betaine. J Bacteriol 190: 2717-2725.

Cheung, K. J., Ba darinarayana, V., Selinger, D. W., Janse, D. and Church, G. M. (2003) A microarray-based antibiotic screen identifies a regulatoty role for supercoiling in the osmotic stress response of Escherichia coli. Genome Res 13: 206-215.

Culham, D. E., Henderson, J., Crane, R. A. and Wood, J. M. (2003) Osmosensor ProP of Escherichia coli responds to the concentration, chemistry, and molecular size of osmolytes in the proteoliposome lumen. Biochemistry 42: 410-420.

Culham, D. E., Romantsov, T. and Wood, J. M. (2008a) Roles of $\mathrm{K}^{+}, \mathrm{H}^{+}, \mathrm{H}_{2} \mathrm{O}$, and DeltaPsi in solute transport mediated by major facilitator superfamily members ProP and LacY. Biochemistry 47: 8176-8185.

Culham, D. E., Vernikovska, Y., Tschowri, N., Keates, R. A., Wood, J. M. and Boggs, J. M. (2008b) Periplasmic loops of osmosensory transporter ProP in Escherichia coli are sensitive to osmolality. Biochemistry 47: 13584-13593.

Dickschat, J. S., Zell, C. and Brock, N. (2010) Pathways and substrate specificity of DMSP catabolism in marine bacteria of the Roseobacter clade. ChemBioChem 11: 417-425.

Eichler, K., Bourgis, F., Buchet, A., Kleber, H. P. and Mandrand-Berthelot, M. A. (1994) Molecular characterization of the cai operon necessary for carnitine metabolism in Escherichia coli. Mol Microbiol 13: 775-786.

Empadinhas, N. and da Costa, M. S. (2008) Osmoadaptation mechanisms in prokaryotes: distribution of compatible solutes. Int Microbiol 11: 151-161.

Faham, S. (2008) The crystal structure of a sodium galactose transporter reveals mechanistic insights into $\mathrm{Na}^{+} /$sugar symport. Science 321: 810-814. 
980 Farwick, M., Siewe, R. M. and Krämer, R. (1995) Glycine betaine uptake after hyperosmotic

981

982

983

984

985

986

987

988

989

990

991

992

993

994

995

996

997

998

999

1000

1001

1002

1003

1004

1005

1006

1007

1008

1009

1010

1011

1012

1013 shift in Corynebacterium glutamicum. J Bacteriol 177: 4690-4695.

Garcia-Estepa, R., Aragona, M., Reina-Bueno, M., Captote, N., Iglesia-Guerra, F., Nieto, J.J. and Vragas, C. (2006) The ectD gene, which is involved in the synthesis of the compatible solute hydroxyectoine, is essential for thermoprotection of the halophilic bacterium Chromohalobacter salexigens. J. Bacteriol. 188: 3774-3784.

Gouaux, E. (2009) The molecular logic of sodium-coupled neurotransmitter transporters. Phil. Trans. R. Soc. B 364: 149-154.

Grammann, K., Volke, A. and Kunte, H. J. (2002) New type of osmoregulated solute transporter identified in halophilic members of the bacteria domain: TRAP transporter TeaABC mediates uptake of ectoine and hydroxyectoine in Halomonas elongata DSM 2581(T). J Bacteriol 184: 3078-3085.

Haardt, M., Kempf, B., Faatz, E. and Bremer, E. (1995) The osmoprotectant proline betaine is a major substrate for the binding-protein-dependent transport system ProU of Escherichia coli K-12. Mol Gen Genet 246: 783-786.

Hagemann, M. (2010) Molecular biology of cyanobacterial salt acclimation. FEMS Microbiol $\operatorname{Rev}$ (in press)

Hanekop, N., Höing, M., Sohn-Bösser, L., Jebbar, M., Schmitt, L. and Bremer, E. (2007) Crystal structure of the ligand-binding protein EhuB from Sinorhizobium meliloti reveals substrate recognition of the compatible solutes ectoine and hydroxyectoine. $J$ Mol Biol 374: 1237-1250.

Holtmann, G. and Bremer, E. (2004) Thermoprotection of Bacillus subtilis by exogenously provided glycine betaine and structurally related compatible solutes: involvement of Opu transporters. J Bacteriol 186: 1683-1693.

Horn, C., Sohn-Bösser, L., Breed, J., Welte, W., Schmitt, L. and Bremer, E. (2006) Molecular determinants for substrate specificity of the ligand-binding protein OpuAC from Bacillus subtilis for the compatible solutes glycine betaine and proline betaine. $J$ Mol Biol 357: 592-606.

Ignatova, Z. and Gierasch, L. M. (2006) Inhibition of protein aggregation in vitro and in vivo by a natural osmoprotectant. Proc Natl Acad Sci USA 103: 13357-13361.

Jardetzky, O. (1966) Simple allosteric model for membrane pumps. Nature 211: 969-970.

Jung, H., Buchholz, M., Clausen, J., Nietschke, M., Revermann, A., Schmid, R. and Jung, K. (2002) CaiT of Escherichia coli, a new transporter catalyzing L-carnitine/gammabutyrobetaine exchange. J Biol Chem 277: 39251-39258. 
1014 Kappes, R. M., Kempf, B. and Bremer, E. (1996) Three transport systems for the

1015

1016

1017

1018

1019

1020

1021

1022

1023

1024

1025

1026

1027

1028

1029

1030

1031

1032

1033

1034

1035

1036

1037

1038

1039

1040

1041

1042

1043

1044

1045

1046 osmoprotectant glycine betaine operate in Bacillus subtilis: characterization of OpuD. J Bacteriol 178: 5071-5079.

Kempf, B. and Bremer, E. (1998) Uptake and synthesis of compatible solutes as microbial stress responses to high-osmolality environments. Arch Microbiol 170: 319-330.

Krämer, R. (2009) Osmosensing and osmosignaling in Corynebacterium glutamicum. Amino Acids 37: 487-497.

Krämer, R. (2010) Bacterial stimulus perception and signal transduction: response to osmotic stress. Chem Rec (in press).

Krishnamurthy, H., Piscitelli, C. L. and Gouaux, E. (2009) Unlocking the molecular secrets of sodium-coupled transporters. Nature 459: 347-355.

Kuhlmann, S. I., Terwisscha van Scheltinga, A. C., Bienert, R., Kunte, H. J. and Ziegler, C. (2008) Osmoregulated transport of compatible solutes in the halophilic bacterium Halomonas elongata: 1.55 A high-resolution structure of the periplasmic ectoinebinding protein from TRAP-transporter TeaABC. Biochemistry 47: 9475-9485.

Laloknam, S., Tanaka, K., Buabooch, T., Waditte, R., Incharoensakdi, A., Hibino, T., Tanaka, T., and Tkabe,T. (2006) Halotolerant cyanobacterium Aphanothece halophytica contains a betaine transporter active at alkaline $\mathrm{pH}$ and high salinity. Appl Environ Microbiol 72: 6018-6026.

Lamark, T., Kaasen, I., Eshoo, M. W., Falkenberg, P., McDougall, J. and Strom, A. R. (1991) DNA sequence and analysis of the bet genes encoding the osmoregulatory cholineglycine betaine pathway of Escherichia coli. Mol Microbiol 5: 1049-1064.

Lamark, T., Rokenes, T. P., McDougall, J. and Strom, A. R. (1996) The complex bet promoters of Escherichia coli: regulation by oxygen (ArcA), choline (BetI), and osmotic stress. J Bacteriol 178: 1655-1662.

Lamark, T., Styrvold, O. B. and Strom, A. R. (1992) Efflux of choline and glycine betaine from osmoregulating cells of Escherichia coli. FEMS Microbiol Lett 75: 149-154.

Lecher, J., Pittelkow, M., Zobel, S., Bursy, J., Bönig, T., Smits, S. H. J., Schmitt, L. and Bremer, E. (2009) The crystal structure of UehA in complex with Ectoine-A comparison with Other TRAP-T binding proteins. J Mol Biol 389: 58-73.

Lolkema, J. S. and Slotboom, D. J. (2008) The major amino acid transporter superfamily has a similar core structure as $\mathrm{Na}^{+}$-galactose and $\mathrm{Na}^{+}$-leucine transporters. $\mathrm{Mol} \mathrm{Membr}$ Biol 25: 567-570. 
1047

1048

1049

1050

1051

1052

1053

1054

1055

1056

1057

1058

1059

1060

1061

1062

1063

1064

1065

1066

1067

1068

1069

1070

1071

1072

1073

1074

1075

1076

1077

1078

1079

1080

Ly, A., Henderson, J., Lu, A., Culham, D. E. and Wood, J. M. (2004) Osmoregulatory systems of Escherichia coli: identification of betaine-carnitine-choline transporter family member BetU and distributions of bet $U$ and $\operatorname{trk} G$ among pathogenic and nonpathogenic isolates. J Bacteriol 186: 296-306.

Mahmood, N. A., Biemans-Oldehinkel, E. and Poolman, B. (2009) Engineering of ion sensing by the cystathionine beta-synthase module of the $\mathrm{ABC}$ transporter OpuA. The J Biol Chem 284: 14368-14376.

Martinac, B., Saimi, Y. and Kung, C. (2008) Ion channels in microbes. Physiol Rev 88: 14491490.

Mikkat, S. and Hagemann, M. (2000) Molecular analysis of the ggtBCD gene cluster of Synechocystis sp. strain PCC6803 encoding subunits of an ABC transporter for osmoprotective compounds. Arch Microbiol 174: 273-282.

Möker, N., Brocker, M., Schaffer, S., Kramer, R., Morbach, S. and Bott, M. (2004) Deletion of the genes encoding the MtrA-MtrB two-component system of Corynebacterium glutamicum has a strong influence on cell morphology, antibiotics susceptibility and expression of genes involved in osmoprotection. Mol Microbiol 54: 420-438.

Möker, N., Kramer, J., Unden, G., Krämer, R. and Morbach, S. (2007) In vitro analysis of the two-component system MtrB-MtrA from Corynebacterium glutamicum. J Bacteriol 189: $3645-36459$.

Nagarajavel, V., Madhusudan, S., Dole, S., Rahmouni, A. R. and Schnetz, K. (2007) Repression by binding of H-NA within the transcription unit. J. Biol Chem 282: 23622-23630.

Noskov, S. Y. and Roux, B. (2008) Control of ion selectivity in LeuT: two $\mathrm{Na}^{+}$binding sites with two different mechanisms. J Mol Biol 377: 804-818.

Oren, A. (1999) Bioenergetic aspects of halophilism. Microbiol Mol Biol Rev 63: 334-348.

Oren, A. (2008) Microbial life at high salt concentrations: phylogenetic and metabolic diversity. Saline Systems 4: 2.

Oswald, C., Smits, S. H., Hoing, M., Sohn-Bosser, L., Dupont, L., Le Rudulier, D., Schmitt, L. and Bremer, E. (2008) Crystal structures of the choline/acetylcholine substratebinding protein ChoX from Sinorhizobium meliloti in the liganded and unligandedclosed states. J Biol Chem 283: 32848-32859.

Ott, V., Koch, J., Späte, K., Morbach, S. and Krämer, R. (2008) Regulatory properties and interaction of the $\mathrm{C}$ - and $\mathrm{N}$-terminal domains of BetP, an osmoregulated betaine transporter from Corynebacterium glutamicum. Biochemistry 47: 12208-12218. 
1081 Özcan, N., Ejsing, C. S., Shevchenko, A., Lipski, A., Morbach, S. and Krämer, R. (2007)

1082

1083

1084

1085

1086

1087

1088

1089

1090

1091

1092

1093

1094

1095

1096

1097

1098

1099

1100

1101

1102

1103

1104

1105

1106

1107

1108

1109

1110

1111

1112 Osmolality, temperature, and membrane lipid composition modulate the activity of betaine transporter BetP in Corynebacterium glutamicum. J Bacteriol 189: 7485-7496.

Özcan, N., Krämer, R. and Morbach, S. (2005) Chill activation of compatible solute transporters in Corynebacterium glutamicum at the level of transport activity. $J$ Bacteriol 187: 4752-4759.

Padan, E., Bibi, E., Ito, M. and Krulwich, T.A. (2005) Alkaline pH homeostasis in bacteria: new insights. Biochim Biohys Acta 1717: 67-88.

Pichereau, V., Pocard, J-A., Hamelin, J., Blanco, C. and Bernard, T. (1998) Differential effects of dimethylsulfoniopropionate, dimethlysulfonioacetate, and other $\mathrm{S}$ methylated compounds on the growth of Sinorhizobium meliloti at low and high osmolarities. Appl Environ Microbiol 64: 1420-1429.

Perozo, E. (2006) Gating prokaryotic mechanosensitive channels. Nat Rev Mol Cell Biol 7: 109-119.

Peter, H., Burkovski, A. and Krämer, R. (1996) Isolation, characterization, and expression of the Corynebacterium glutamicum betP gene, encoding the transport system for the compatible solute glycine betaine. J Bacteriol 178: 5229-5234.

Peter, H., Burkovski, A. and Kramer, R. (1998a) Osmo-sensing by N- and C-terminal extensions of the glycine betaine uptake system BetP of Corynebacterium glutamicum. J Biol Chem 273: 2567-2574.

Peter, H., Weil, B., Burkovski, A., Krämer, R. and Morbach, S. (1998b) Corynebacterium glutamicum is equipped with four secondary carriers for compatible solutes: identification, sequencing, and characterization of the proline/ectoine uptake system, ProP, and the ectoine/proline/glycine betaine carrier, EctP. J Bacteriol 180: 60056012.

Poolman, B., Blount, P., Folgering, J. H., Friesen, R. H., Moe, P. C. and van der Heide, T. (2002) How do membrane proteins sense water stress? Mol Microbiol 44: 889-902.

Poolman, B. and Glaasker, E. (1998) Regulation of compatible solute accumulation in bacteria. Mol Microbiol 29: 397-407.

Poolman, B., Spitzer, J. J. and Wood, J. M. (2004) Bacterial osmosensing: roles of membrane structure and electrostatics in lipid-protein and protein-protein interactions. Biochim Biophys Acta 1666: 88-104. 
1113 Record, M. T., Jr., Courtenay, E. S., Cayley, D. S. and Guttman, H. J. (1998) Responses of E.

1114

1115

1116

1117

1118

1119

1120

1121

1122

1123

1124

1125

1126

1127

1128

1129

1130

1131

1132

1133

1134

1135

1136

1137

1138

1139

1140

1141

1142

1143

1144

1145 coli to osmotic stress: large changes in amounts of cytoplasmic solutes and water. TIBS 23: 143-148.

Ressl, S., Terwisscha van Scheltinga, A. C., Vonrhein, C., Ott, V. and Ziegler, C. (2009) Molecular basis of transport and regulation in the $\mathrm{Na}^{+} /$betaine symporter BetP. Nature 458: $47-52$.

Romantsov, T., Guan, Z. and Wood, J. M. (2009) Cardiolipin and the osmotic stress responses of bacteria. Biochim Biophys Acta 1788: 2092-2100.

Romeo, Y., Bouvier, J. and Gutierrez, C. (2007) Osmotic regulation of transcription in Lacococcus lactis: ionic-strenght-dependent binding of the BusR repressor to the busA promoter. FEBS Lett. 581: 3387-3390.

Rosenstein, R., Futter-Bryniok, D. and Götz, F. (1999) The choline-converting pathway in Staphylococcus xylosus C2A: genetic and physiological characterization. J Bacteriol 181: 2273-2278.

Rosenthal, A. Z., Kim, Y. and Gralla, J. D. (2008) Poising of the Escherichia coli RNA polymerase and its release from the sigma $38 \mathrm{C}$-terminal tail for $o s m Y$ transcription. $J$ Mol Biol 376: 9-38-949.

Rösgen, J. (2007) Molecular basis of osmolyte effects on protein and metabolites. Methods in Enzymol 428: 459-486.

Rösgen, J. (2009) Molecular crowding and solvation: direct and indirect impact on protein reactions. Methods in molecular biology (Clifton, N.J 490: 195-225.

Rübenhagen, R., Morbach, S. and Krämer, R. (2001) The osmoreactive betaine carrier BetP from Corynebacterium glutamicum is a sensor for cytoplasmic $\mathrm{K}^{+}$. EMBO J 20: 5412 5420.

Rübenhagen, R., Rönsch, H., Jung, H., Krämer, R. and Morbach, S. (2000) Osmosensor and osmoregulator properties of the betaine carrier BetP from Corynebacterium glutamicum in proteoliposomes. J Biol Chem 275: 735-741.

Saier, M. H., Jr. (2000) A functional-phylogenetic classification system for transmembrane solute transporters. Microbiol Mol Biol Rev 64: 354-411.

Saier, M. H., Jr., Yen, M. R., Noto, K., Tamang, D. G. and Elkan, C. (2009) The transporter classification database: recent advances. Nucleic Aacids Res 37: D274-278..

Schiefner, A., Breed, J., Bosser, L., Kneip, S., Gade, J., Holtmann, G., Diederichs, K., Welte, W. and Bremer, E. (2004a) Cation-pi interactions as determinants for binding of the 
1146

1147

1148

1149

1150

1151

1152

1153

1154

1155

1156

1157

1158

1159

1160

1161

1162

1163

1164

1165

1166

1167

1168

1169

1170

1171

1172

1173

1174

1175

1176

1177

1178

1179

compatible solutes glycine betaine and proline betaine by the periplasmic ligandbinding protein ProX from Escherichia coli. J Biol Chem 279: 5588-5596.

Schiefner, A., Holtmann, G., Diederichs, K., Welte, W. and Bremer, E. (2004b) Structural basis for the binding of compatible solutes by ProX from the hyperthermophilic archaeon Archaeoglobus fulgidus. J Biol Chem 279: 48270-48281.

Schiller, D., Ott, V., Krämer, R. and Morbach, S. (2006) Influence of membrane composition on osmosensing by the betaine carrier BetP from Corynebacterium glutamicum. The $J$ Biol Chem 281: 7737-7746.

Schiller, D., Rübenhagen, R., Krämer, R. and Morbach, S. (2004) The C-terminal domain of the betaine carrier BetP of Corynebacterium glutamicum is directly involved in sensing $\mathrm{K}^{+}$as an osmotic stimulus. Biochemistry 43: 5583-5591.

Schulze, S., Köster, S., Geldmacher, U., Terwisscha van Scheltinga, A. C. and Kühlbrandt, W. (2010) Structural basis of $\mathrm{Na}^{+}$-independent and cooperative substrate/product antiport in CaiT. Nature (in press).

Shaffer, P. L., Goehring, A., Shankaranarayanan, A. and Gouaux, E. (2009) Structure and mechanism of a $\mathrm{Na}^{+}$-independent amino acid transporter. Science 325: 1010-1014.

Sheehan, V. M., Sleator, R. D., Fitzgerald, G. F. and Hill, C. (2006) Heterologous expression of BetL, a betaine uptake system, enhances the stress tolerance of Lactobacillus salivarius UCC118. Appl Environ Microbiol 72: 2170-2177.

Singh, S., Yamashita, A. and Gouaux, E. (2007) Antidepressant binding site in a bacterial homologue of neurotransmitter transporters. Nature 448: 952-956.

Singh, S. K., Piscitelli, C. L., Yamashita, A. and Gouaux, E. (2008) A competitive inhibitor traps LeuT in an open-to-out conformation. Science 322: 1655-1661.

Smits, S. H., Hoing, M., Lecher, J., Jebbar, M., Schmitt, L. and Bremer, E. (2008) The compatible-solute-binding protein OpuAC from Bacillus subtilis: ligand binding, sitedirected mutagenesis, and crystallographic studies. J Bacteriol 190: 5663-5671.

Spiegelhalter, F. and Bremer, E. (1998) Osmoregulation of the $o p u E$ proline transport gene from Bacillus subtilis - contributions of the $\sigma^{\mathrm{A}}$ - and $\sigma^{\mathrm{B}}$-dependent stress-responsive promoters. Mol Microbiol 29: 285-296.

Steger, R., Weinand, M., Krämer, R. and Morbach, S. (2004) LcoP, an osmoregulated betaine/ectoine uptake system from Corynebacterium glutamicum. FEBS Lett 573: 155-160.

Street, T. O., Bolen, D. W. and Rose, G. D. (2006) A molecular mechanism for osmolyteinduced protein stability. Proc Natl Acad Sci U S A 103: 13997-14002. 
1180

1181

1182

1183

1184

1185

1186

1187

1188

1189

1190

1191

1192

1193

1194

1195

1196

1197

1198

1199

1200

1201

1202

1203

1204

1205

1206

1207

1208

1209

1210

1211

1212

Street, T. O., Krukenberg, K. A., Rosgen, J., Bolen, D. W. and Agard, D. A. (2010) Osmolyte-induced conformational changes in the Hsp90 molecular chaperone. Protein Sci 19: 57-65.

Tang, L., Bai, L., Wang, W-h and Jiang, T. (2010) Crystal structure of the carnitine transporter and insights into the antiport mechanism. Natr Struct Mol Biol 17: 492496.

Tanghe, A., Van Dijck, P. and Thevelein, J. M. (2006) Why do microorganisms have aquaporins? Trends Microbiol 14: 78-85.

Todd, J. D., Curson, A. R., Nikolaidou-Katsaraidou, N., Brearley, C. A., Watmough, N. J., Chan, Y., Page, P. C., Sun, L. and Johnston, A. W. (2010) Molecular dissection of bacterial acrylate catabolism - unexpected links with dimethylsulfoniopropionate catabolism and dimethyl sulfide production. Environ Microbiol 21: 327-343.

Tondervik, A. and Strom, A. R. (2007) Membrane topology and mutational analysis of the osmotically activated BetT choline transporter of Escherichia coli. Microbiology 153: 803-813.

van der Heide, T. and Poolman, B. (2000) Osmoregulated ABC-transport system of Lactococcus lactis senses water stress via changes in the physical state of the membrane. Proc Natl Acad Sci U S A 97: 7102-7106.

van der Heide, T., Stuart, M. C. and Poolman, B. (2001) On the osmotic signal and osmosensing mechanism of an $\mathrm{ABC}$ transport system for glycine betaine. EMBO J 20: 7022-7032.

Vial-Costa, M., Rinta-Kato, J. M., Sun, S., Sharma, S., Potestky, R. and Moran, M.A. (2010) Transcriptomic analysis of a bacterial community enriched with dimethylsulfoniopropionate. ISME J (in press).

Vinothkumar, K. R., Raunser, S., Jung, H. and Kuhlbrandt, W. (2006) Oligomeric structure of the carnitine transporter CaiT from Escherichia coli. J Biol Chem 281: 4795-4801.

Welsh, D. T. (2000) Ecological significance of compatible solute accumulation by microorganisms: from single cells to global climate. FEMS Microbiol Rev 24: 263-290.

Weyand, S. (2008) Structure and molecular mechanism of a nucleobase-cation-symport-1 family transporter. Science 322: 709-713.

Wolters, J.C., Berntsson, R.P., Gul, N., Karasawa, A., Thunnissen, A.M., Slotboom, D.J. and Poolman, B. (2010) Ligand binding and crystal structures of the substrate-binding domain of the ABC transporter OpuA. PLoS One 5: e10361 
1213 Wood, J. M. (1999) Osmosensing by bacteria: signals and membrane-based sensors. Microbiol Mol Biol Rev 63: 230-262.

Wood, J. M. (2006) Osmosensing by bacteria. Sci STKE 357: pe 43.

Wood, J. M., Bremer, E., Csonka, L. N., Krämer, R., Poolman, B., van der Heide, T. and Smith, L. T. (2001) Osmosensing and osmoregulatory compatible solute accumulation by bacteria. Comp Biochem Physiol A Mol Integr Physiol 130: 437-460.

Yamashita, A., Singh, S. K., Kawate, T., Jin, Y. and Gouaux, E. (2005) Crystal structure of a bacterial homologue of $\mathrm{Na}^{+} / \mathrm{Cl}^{-}$-dependent neurotransmitter transporters. Nature 437: 215-223.

Yancey, P. H., Clark, M. E., Hand, S. C., Bowlus, R. D. and Somero, G. N. (1982) Living with water stress: the evolution of osmolyte systems. Science 217: 1214-1222.

Yancey, P. H. (2005) Organic osmolytes as compatible, metabolic and counteracting cytoprotectants in high osmolarity and other stresses. J Exp Biol 208: 2819-2830.

Zhou, Z. (2007) LeuT-desipramine structure reveals how antidepressants block neurotransmitter uptake. Science 317: 1390-1393.

Ziegler, C., Morbach, S., Schiller, D., Kramer, R., Tziatzios, C., Schubert, D. and Kuhlbrandt, W. (2004) Projection structure and oligomeric state of the osmoregulated sodium/glycine betaine symporter BetP of Corynebacterium glutamicum. J Mol Biol 337: $1137-1147$.

\section{Legends to Figures:}

Fig. 1. Osmotically driven water fluxes across the cytoplasmic membrane of a microbial cell exposed either to hyper- or hypo-osmotic surroundings.

Fig. 2. Known substrates for BCCT carriers. The positively charged nitrogen or sulfur headgroups and the delocalized positive charge present in ectoine and hydroxyectoine are highlighted.

Fig. 3. Activation profile of the BetP transporter embedded in different membranes. The rate of glycine betaine uptake was measured as a function of the osmolarity of the surrounding medium, either in the native membrane of C. glutamicum (red line), after heterologous expression in E. coli (green line), or after isolation, purification and reconstitution into proteoliposomes (blue line). The maximum activity measured was set to $100 \%$, the absolute 
1247 values are in the range of $30-80 \mu \mathrm{moles} /(\mathrm{min} \cdot \mathrm{mg} \mathrm{dw})^{-1}$ for cells and about $1000-2000$ $\mu$ moles/(min $\cdot \operatorname{mg}$ protein $)^{-1}$ for proteoliposomes.

Fig. 4. Schematic representation of the catalytic and the activation (regulatory) cycle of the BetP transporter. In the activation cycle, BetP $(\mathrm{C}=$ carrier $)$ occurs either in the active $\left(\mathrm{C}^{*}\right.$, blue and yellow colour) or the inactive state $(\mathrm{C}$, red colour). In the catalytic cycle, BetP exposes its glycine betaine substrate-binding site either to the periplasmic space $\left(\mathrm{C}^{*}\right.$, carrier protein symbol open to the top) or to the cytoplasmic space $\left(\mathrm{C}^{*}\right.$, carrier protein symbol open to the bottom). Alternatively, the substrate-binding site is occluded (yellow colour) from the surroundings. Substrate (S) denotes one molecule of glycine betaine (B; black triangel) together with $2 \mathrm{Na}^{+}$ions (green circles). In the course of one round of the catalytic cycle of the BetP carrier, one molecule of glycine betaine and two $\mathrm{Na}^{+}$ions are translocated across the plasma membrane.

Fig. 5. Crystal structure of BetP from C. glutamicum and CaiT from E. coli in complex with their ligands. (A) Periplasmic view on the BetP trimer (resolved to a resolution of $3.35 \AA$ ) in spiral presentation and on the CaiT trimer (resolved to a resolution of $3.5 \AA$ ). Individual subunits are coloured in blue, red and green (B) Side view on the BetP and CaiT trimers. The C-terminal domain of subunit 1 from the BetP trimer assembly is shown to protrude $35 \AA$ into the cytoplasm.

Fig. 6. Toplogical organization of BetP within the plain of the cytoplasmic membrane. (A) Top view on a BetP subunit with a colouring of the TM helices assigned according to BetP's topology (B) showing the organization of the two structural repeats.

Fig. 7. Structural features and ligand binding sites of BetP and CaiT. (A) Side view on the $C$. glutamicum BetP structure in complex with one molecule of glycine betaine; the CaiT structure from E. coli in complex with four L-carnitine molecules and the CaiT structure from P. mirabilis in complex with two $\gamma$-butyrobetaine molecules. (B) Structural features of the central ligand-binding site in BetP and CaiT. The aromatic ligand-binding boxes coordinating the substrate glycine betaine, L-carnitine or $\gamma$-butyrobetaine are highlighted. section through the BetP and CaiT structures revealing an occluded state for BetP and an inward-facing state for CaiT, respectively. 
1281 Fig. 8. Osmoregulatory interactions within the BetP trimer. Spatial interaction of the C1282 terminal domain of one subunit (monomer 1) of BetP with charged residues in loop 2 and 1283 loop 8 of the adjacent BetP subunit (monomer 3), which is suggested to be of significance for 1284 activity regulatory. (A) Under low external osmolarity and/or absence of $\mathrm{K}^{+}$ions (inactive conditions) the BetP carrier is locked in a resting conformation with the bound two $\mathrm{Na}^{+}$ions

1286 (green circles) and glycine betaine (B; black triangle) occluded from the cytoplasmic side. (B) 1287 Under hyperosmotic conditions and increasing concentrations of $\mathrm{K}^{+}$ions (grey spheres) in the cytoplasm and stimuli perceived via the membrane, the BetP carrier initiates a orientation/conformation change of its C-terminal domain which alters the interaction network and allows a conformational change of the TM helices of the inverted repeats. As a consequence, glycine betaine can be released into the cytoplasm. The role of the N-terminal domain of BetP (monomer 3) in this interaction switching is currently not firmly understood.

1293 It is suggested that the negative charge clusters in BetP (red spheres) interact with the positive 1294 charge clusters (blue spheres) present the C-terminal domain of BetP (picture kindly provided 1295 by Susanne Ressl). 


\begin{tabular}{|c|c|c|c|c|c|c|c|}
\hline $\begin{array}{l}\text { Transporter } \\
\text { [citation] }\end{array}$ & $\begin{array}{l}\text { Organism } \\
\text { (Accession number) }\end{array}$ & $\begin{array}{l}\text { Molecu } \\
\text { Substrate }\end{array}$ & $\begin{array}{l}\text { Microb } \\
\text { Predicted } \\
\text { driving } \\
\text { force/ } \\
\text { direction }\end{array}$ & $\begin{array}{l}\text { Total } \\
\text { number } \\
\text { aa }\end{array}$ & $\begin{array}{l}\text { Sequence } \\
\text { identity } \\
\text { to BetP } \\
{[\%]}\end{array}$ & $\begin{array}{l}\mathrm{N}- \\
\text { terminal } \\
\text { domain } \\
{[\text { aa] }}\end{array}$ & $\begin{array}{l}\mathrm{C}- \\
\text { terminal } \\
\text { domatn } \\
\text { [aa] }\end{array}$ \\
\hline BetP $[1]$ & $\begin{array}{l}\text { Corynebacterium } \\
\text { glutamicum } \\
\text { CAA63771.1 }\end{array}$ & GB & $\begin{array}{l}\text { smf / } \\
\text { symport }\end{array}$ & 595 & 100 & 58 & 50 \\
\hline
\end{tabular}

1315

\begin{tabular}{|c|c|c|c|c|c|c|c|}
\hline BetP [1] & $\begin{array}{l}\text { Corynebacterium } \\
\text { glutamicum } \\
\text { CAA63771.1 }\end{array}$ & GB & $\begin{array}{l}\text { smf / } \\
\text { symport }\end{array}$ & 595 & 100 & 58 & 50 \\
\hline OpuD [2] & $\begin{array}{l}\text { Bacillus subtilis } \\
\text { AAC44368.1 }\end{array}$ & GB & $\begin{array}{l}\text { smf / } \\
\text { symport }\end{array}$ & 512 & 43 & 4 & 24 \\
\hline BetL [3] & $\begin{array}{l}\text { Listeria monocytogenes } \\
\text { AAD30266.1 }\end{array}$ & GB & $\begin{array}{l}\text { smf / } \\
\text { symport }\end{array}$ & 507 & 41 & 3 & 20 \\
\hline BetH [4] & $\begin{array}{l}\text { Halobacillus trueperi } \\
\text { AAT3760.1 }\end{array}$ & GB & $\begin{array}{l}\text { smf / } \\
\text { symport }\end{array}$ & 505 & 41 & 3 & 18 \\
\hline BetM [5] & $\begin{array}{l}\text { Marinococcus halophilus } \\
\text { AAQ67247.1 }\end{array}$ & GB & $\begin{array}{l}\text { smf / } \\
\text { symport }\end{array}$ & 493 & 38 & 3 & 7 \\
\hline ButA [6] & $\begin{array}{l}\text { Tetragenococcus } \\
\text { halophila } \\
\text { AAP06751.1 }\end{array}$ & GB & $\begin{array}{l}\text { smf/ } \\
\text { symport }\end{array}$ & 608 & 34 & 51 & 70 \\
\hline OpuD [7] & $\begin{array}{l}\text { Vibrio cholerae } \\
\text { AAF944381.1 }\end{array}$ & GB & $\begin{array}{l}\text { smf / } \\
\text { symport }\end{array}$ & 539 & 33 & 34 & 15 \\
\hline $\begin{array}{ll}\text { BetT } & {[8]}\end{array}$ & $\begin{array}{l}\text { Haemophilus influenza } \\
\text { AAC23352.1 }\end{array}$ & ?* & ? & 669 & 32 & 7 & 174 \\
\hline $\begin{array}{ll}\text { Bet T } & \text { [9] }\end{array}$ & $\begin{array}{l}\text { Aphanothece halophytica } \\
\text { BAF03065.1 }\end{array}$ & GB & $\begin{array}{l}\text { smf / } \\
\text { symport }\end{array}$ & 564 & 32 & 36 & 38 \\
\hline BetP [7] & $\begin{array}{l}\text { Vibrio parahaemolyticus } \\
\text { BAC60168. }\end{array}$ & GB & $\begin{array}{l}\text { smf / } \\
\text { symport }\end{array}$ & 523 & 32 & 41 & 14 \\
\hline $\begin{array}{ll}\text { BetU } & {[10]}\end{array}$ & $\begin{array}{l}\text { Escherichia coli } \\
\text { AAQ10261.1 }\end{array}$ & GB & $\begin{array}{l}\text { smf / } \\
\text { symport }\end{array}$ & 667 & 31 & 17 & 162 \\
\hline BetS $\quad[11]$ & $\begin{array}{l}\text { Sinorhizobium meliloti } \\
\text { AAL37253.1 }\end{array}$ & GB/PB & $\begin{array}{l}\text { smf / } \\
\text { symport }\end{array}$ & 706 & 31 & 52 & 167 \\
\hline $\begin{array}{ll}\text { DddT } & {[12]}\end{array}$ & $\begin{array}{l}\text { Psychrobacter sp. } \\
\text { ACY02893.1 }\end{array}$ & $\begin{array}{l}\text { GB/ } \\
\text { DMSP }\end{array}$ & $\begin{array}{l}\text { smf / } \\
\text { symport }\end{array}$ & 550 & 28 & 25 & 17 \\
\hline LcoP [13] & $\begin{array}{l}\text { Corynebacterium } \\
\text { glutamicum } \\
\text { CAF20998.1 }\end{array}$ & $\mathrm{E} / \mathrm{GB}$ & $\begin{array}{l}\text { smf / } \\
\text { symport }\end{array}$ & 630 & 37 & 43 & 96 \\
\hline EctT & $\begin{array}{l}\text { Virgibaccilus } \\
\text { pantothenticus } \\
\text { AAL16076.1 } \\
\end{array}$ & $\mathrm{E} / \mathrm{HE}$ & $\begin{array}{l}\text { smf / } \\
\text { symport }\end{array}$ & 501 & 36 & 6 & 11 \\
\hline EctM [5] & $\begin{array}{l}\text { Marinococcus halophilus } \\
\text { AAQ67247.1 }\end{array}$ & $\mathrm{E} / \mathrm{HE}$ & $\begin{array}{l}\text { smf / } \\
\text { symport }\end{array}$ & 493 & 33 & 10 & 25 \\
\hline EctP & $\begin{array}{l}\text { Corynebacterium } \\
\text { glutamicum } \\
\text { CAA04760.1 }\end{array}$ & $\mathrm{E} / \mathrm{P} / \mathrm{GB}$ & $\begin{array}{l}\text { smf / } \\
\text { symport }\end{array}$ & 615 & 29 & 21 & 102 \\
\hline BetT $\quad[16]$ & $\begin{array}{l}\text { Pseudomonas syringae } \\
\text { ZP_03399554 }\end{array}$ & $\mathrm{Ch} / \mathrm{ACh}$ & $\begin{array}{l}\text { pmf / } \\
\text { symport }\end{array}$ & 664 & 30 & 14 & 160 \\
\hline BetT [17] & $\begin{array}{l}\text { Escherichia coli } \\
\text { CAQ30790.1 }\end{array}$ & $\mathrm{Ch}$ & $\begin{array}{l}\text { pmf / } \\
\text { symport }\end{array}$ & 677 & 30 & 14 & 175 \\
\hline $\begin{array}{ll}\text { CudT } & {[18]}\end{array}$ & $\begin{array}{l}\text { Staphylococcus xylosus } \\
\text { AAD23898 }\end{array}$ & $\mathrm{Ch}$ & $\begin{array}{l}\text { pmf / } \\
\text { symport }\end{array}$ & 540 & 30 & 7 & 36 \\
\hline CaiT [19] & $\begin{array}{l}\text { Escherichia coli } \\
\text { CAQ30560.1 }\end{array}$ & $\mathrm{CT} / \gamma-\mathrm{BB}$ & $\begin{array}{l}\text { Substrate: } \\
\text { product } \\
\text { antiport }\end{array}$ & 504 & 25 & 10 & 5 \\
\hline PmCaiT [20] & $\begin{array}{l}\text { Proteus mirabilis } \\
\text { YP_002152355.1 }\end{array}$ & $\mathrm{CT} / \gamma-\mathrm{BB}$ & $\begin{array}{l}\text { Substrate: } \\
\text { product } \\
\text { antiport }\end{array}$ & 514 & 25 & 15 & 10 \\
\hline
\end{tabular}

1316 Table 1. Functionally characterized members of the BCCT family 


\section{References for Table 1:}

1321 [1] Peter et al., (1996) J. Bacteriol. 178: 5229-5234; [2] Kappes, et al., (1996) J. Bacteriol. 1322 178: 5071-5079; [3] Sleator et al., (1999) Appl Environ Microbiol 65: 2078-2083; [4] Lu et 1323 al., (2004) FEMS Microbiol Lett 235: 393-399; [5] Vermeulen et al., (2004) Extremophiles 8: 1324 175-184; [6] Baliarda et al., (2003) Curr Microbiol 47: 347-351; [7] Naughton et al., (2009) 1325 Appl Environ Microbiol 75: 2802-10; [8] Fan et al., (2003) Mol Microbiol 50: 537-48; [9] 1326 Laloknam et al., (2006) Appl Environ Microbiol 72: 6018-26; [10] Ly et al., (2004) J 1327 Bacteriol 186: 296-306; [11] Boscari et al., (2002) J Bacteriol 184: 2654-2663; [12] Todd et 1328 al., (2010) Environ Microbiol 21: 327-343: [13] Steger et al., (2004) FEBS Lett 573: 1551329 160; [14] Kuhlmann et al., unpublished data; [15] Weinand et al. (2007) Appl Microbiol 1330 Biotechnol 76: 701-708; [16] Chen and Beattie, (2008) J Bacteriol 190: 2717-2725; [17] 1331 Lamark et al., (1991) Mol. Microbiol 5: 1049-1064; [18] Rosenstein et al., (1999) J Bacteriol 1332 181: 2273-2278; [19] Eichler et al., (1994) Mol Microbiol 13: 775-786; [20] Schulze et al., 1333 (2010) Nature (in press)

$1334 *$ The BetT protein from Haemophilus influenzae was suggested to function in the uptake of 1335 [Fan et al., (2003) Mol Microbiol 50: 537-48] but the actual substrate has not been 1336 unambiguously determined. 


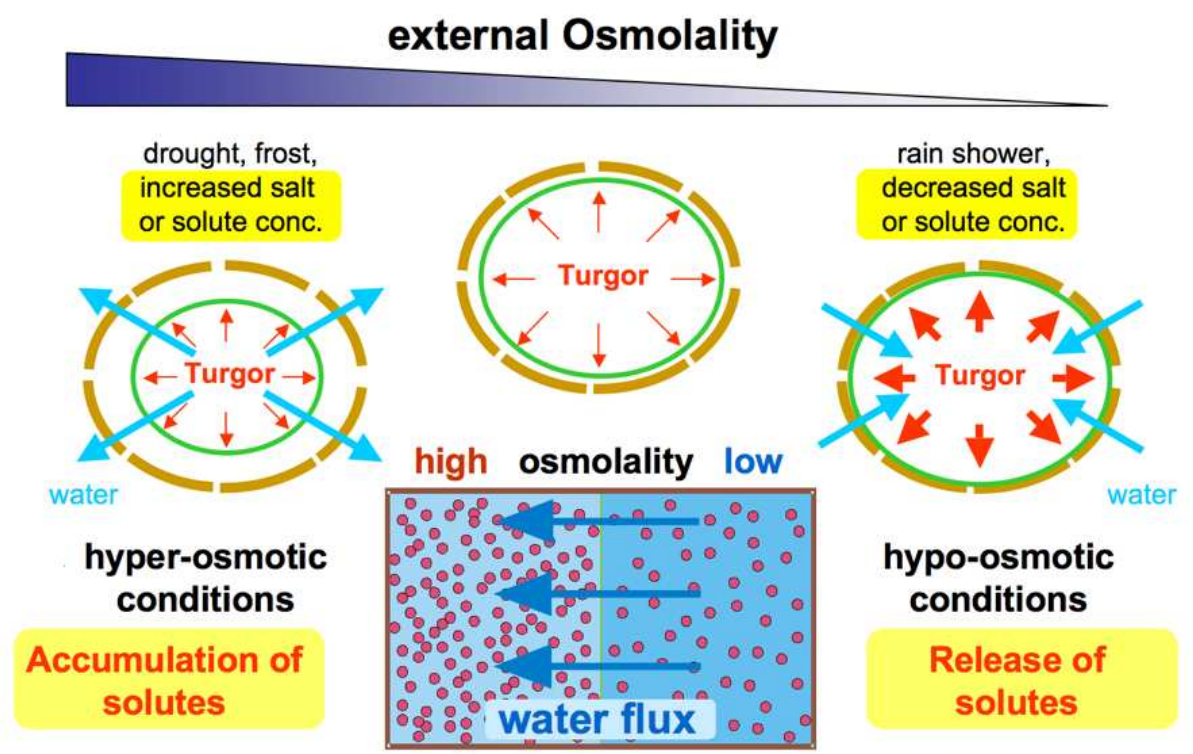

$339 \times 262 \mathrm{~mm}(72 \times 72$ DPI $)$ 


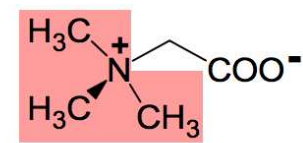

Glycine betaine<smiles>CC(O)C[N+](C)(C)C</smiles>

Choline<smiles>CC(=O)OCC[N+](C)(C)C</smiles>

Acetylcholine<smiles>C[N+](C)(C)CC(O)CC(=O)[O-]</smiles>

L-carnitine

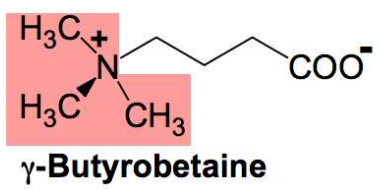

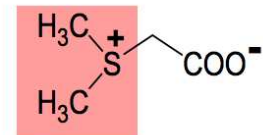

Dimethylsulfonioacetate (DMSA)

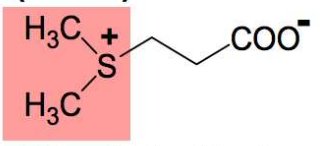

Dimethylsulfoniopropionate (DMSP)

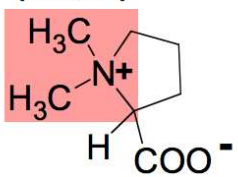

Prolinebetaine
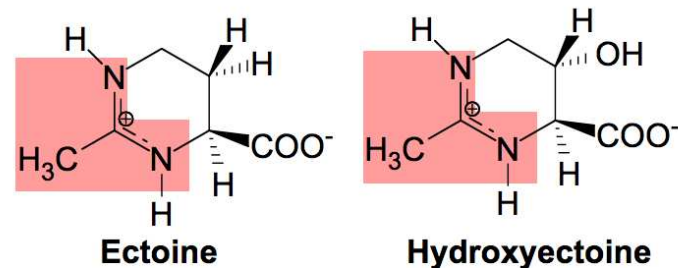

Hydroxyectoine 


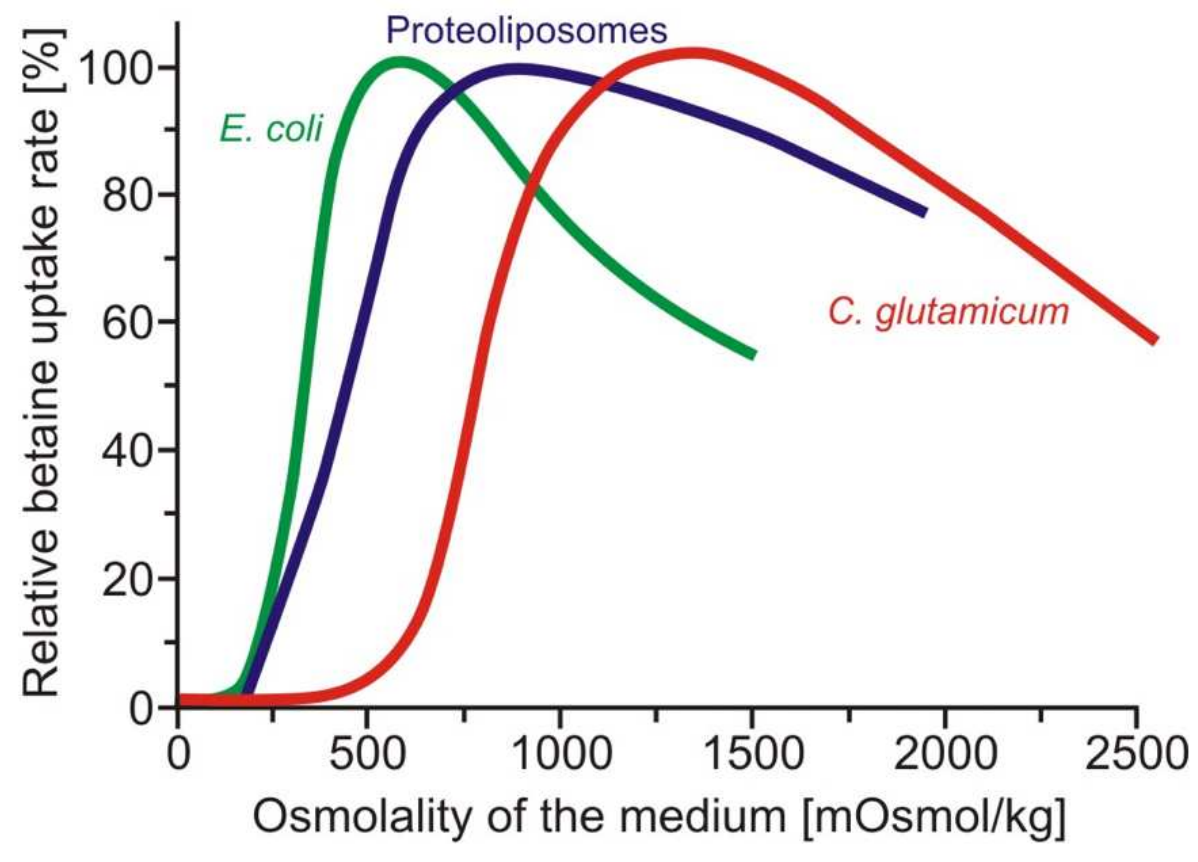

$339 \times 281 \mathrm{~mm}(72 \times 72$ DPI $)$ 


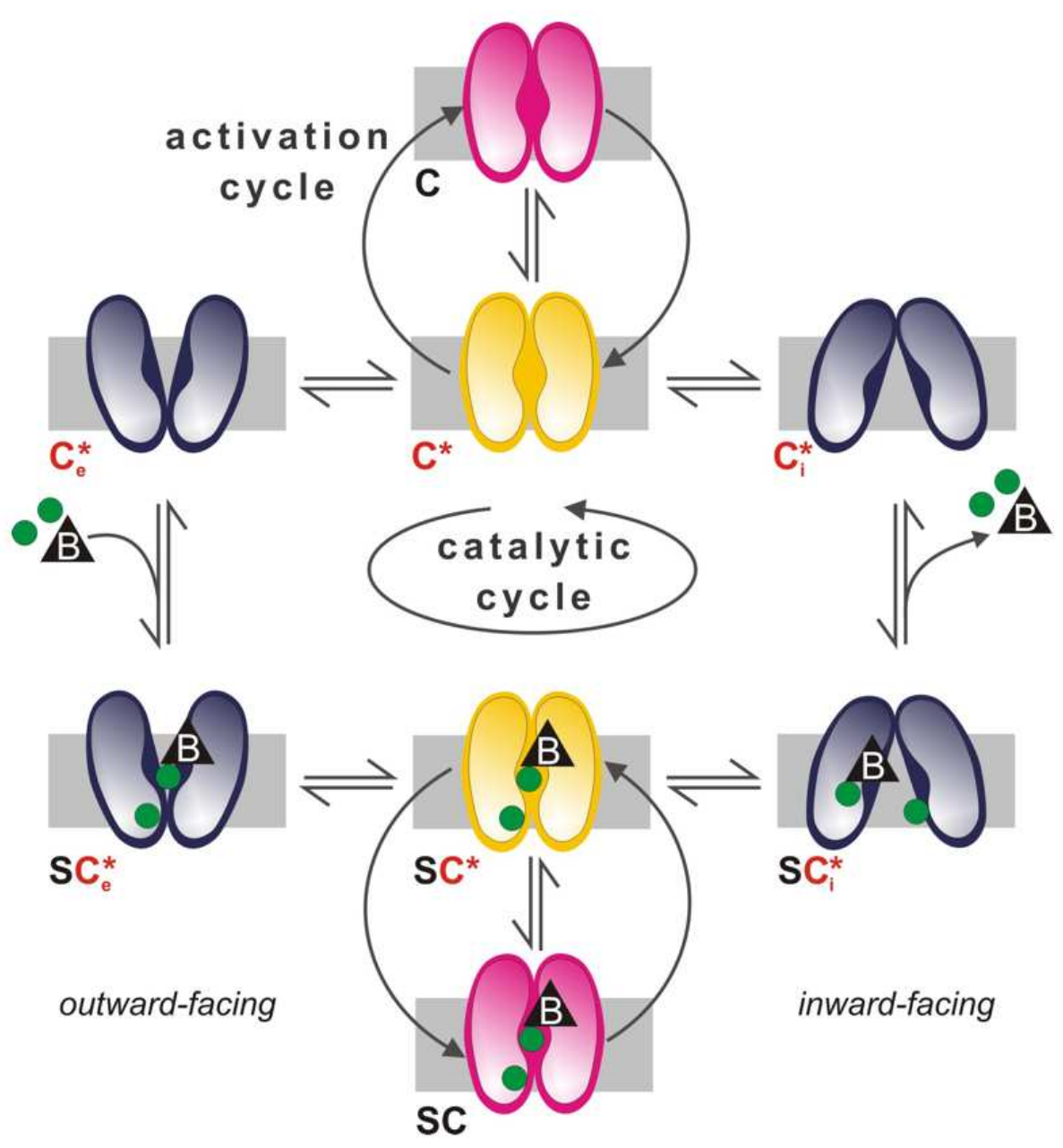

$304 \times 317 \mathrm{~mm}(72 \times 72$ DPI $)$ 
A BetP + glycine betaine

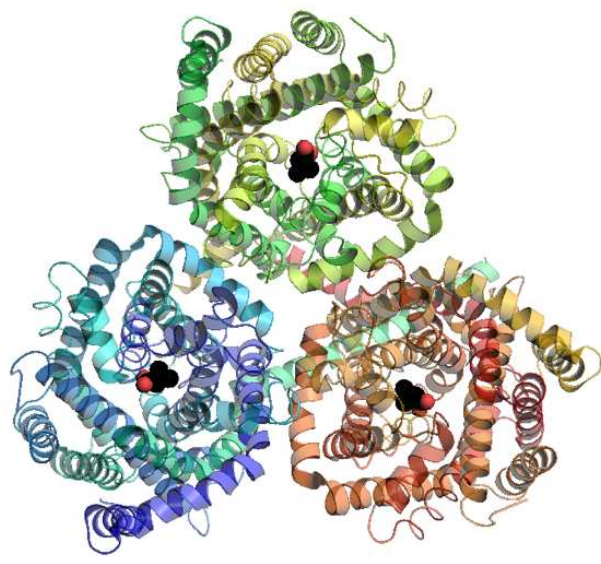

B

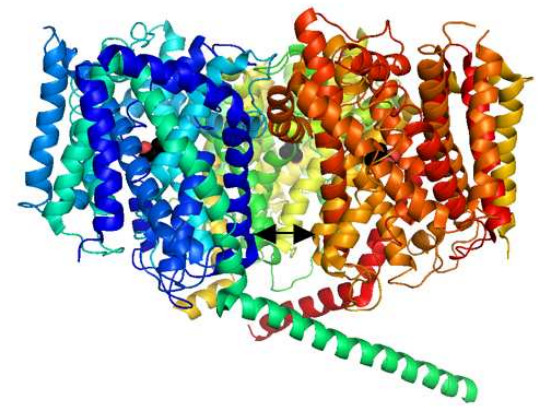

CaiT $+\gamma$-butyrobetaine
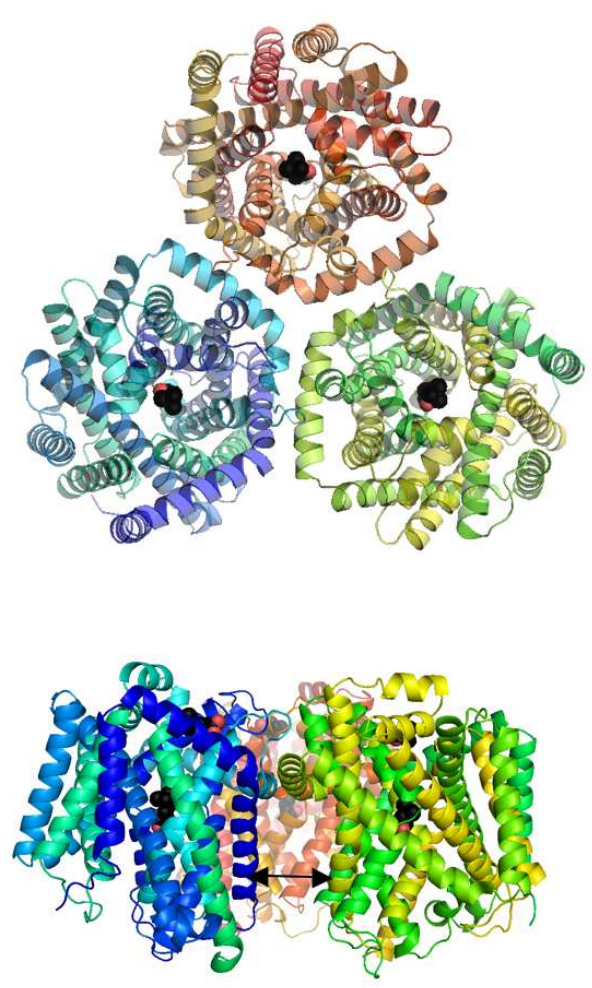

$420 \times 366 \mathrm{~mm}(72 \times 72 \mathrm{DPI})$ 
A

B

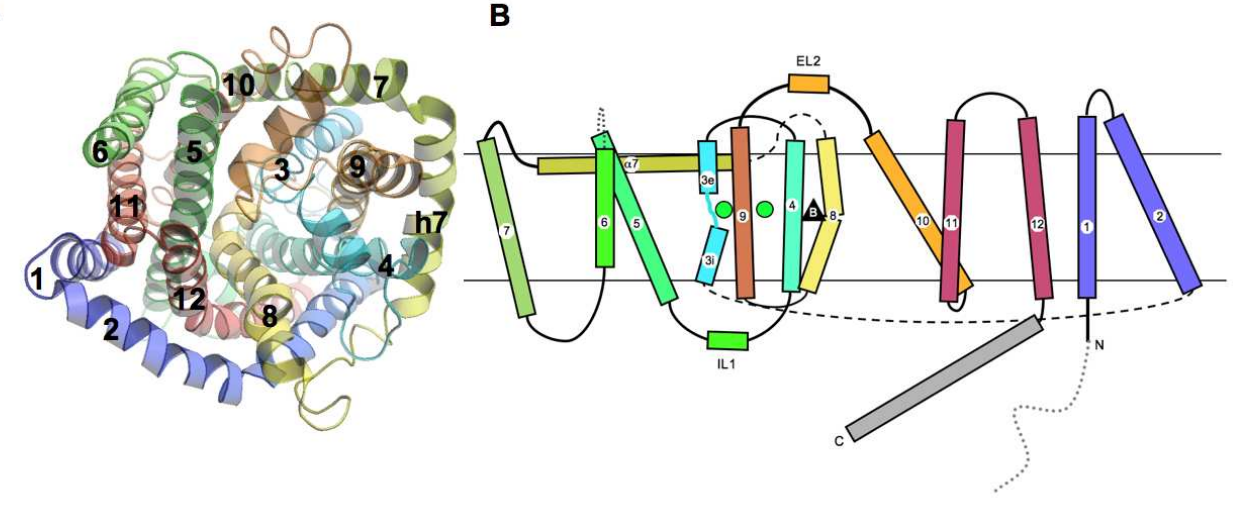

$454 \times 212 \mathrm{~mm}(72 \times 72 \mathrm{DPI})$ 


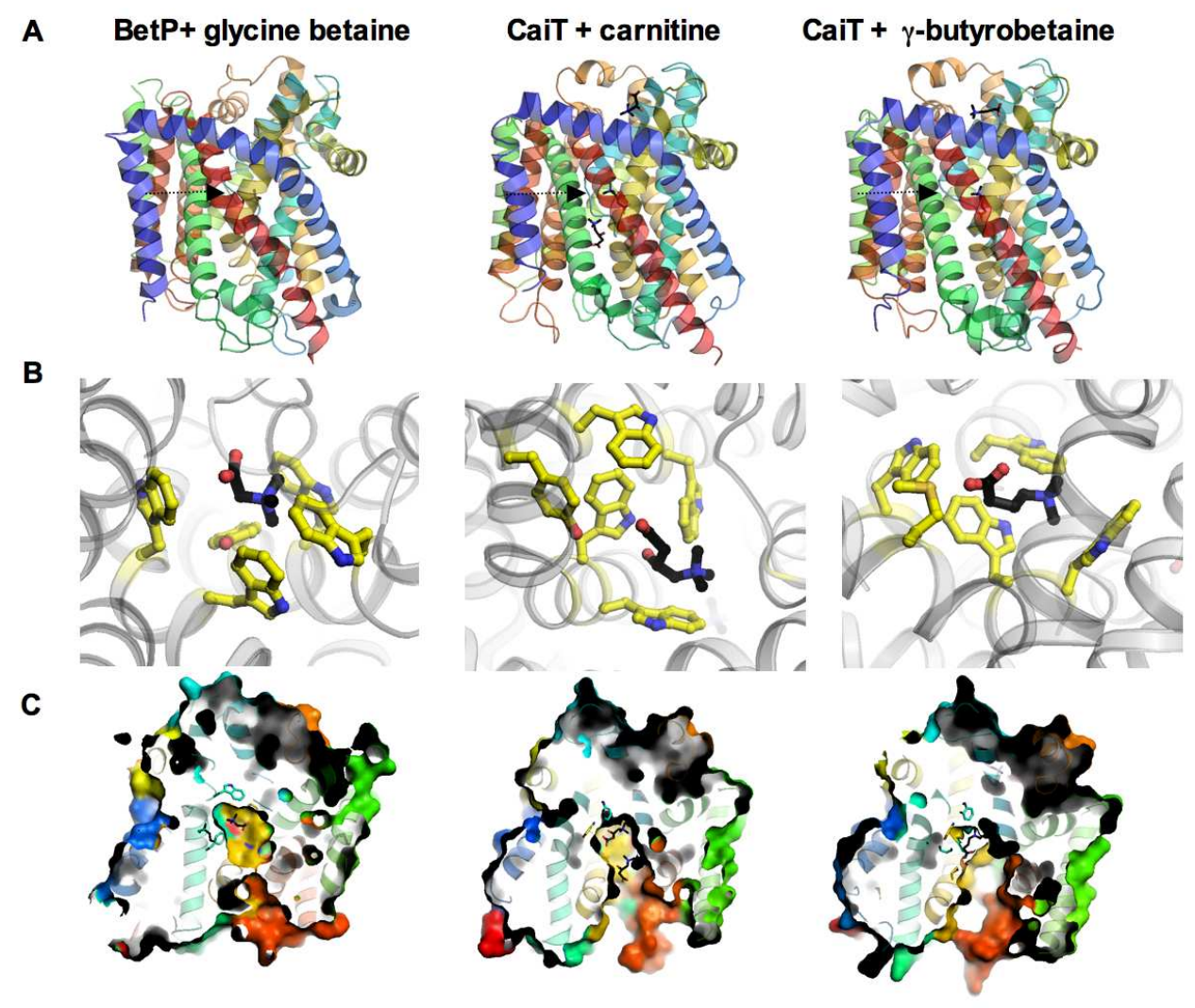

$443 \times 375 \mathrm{~mm}(72 \times 72$ DPI $)$ 

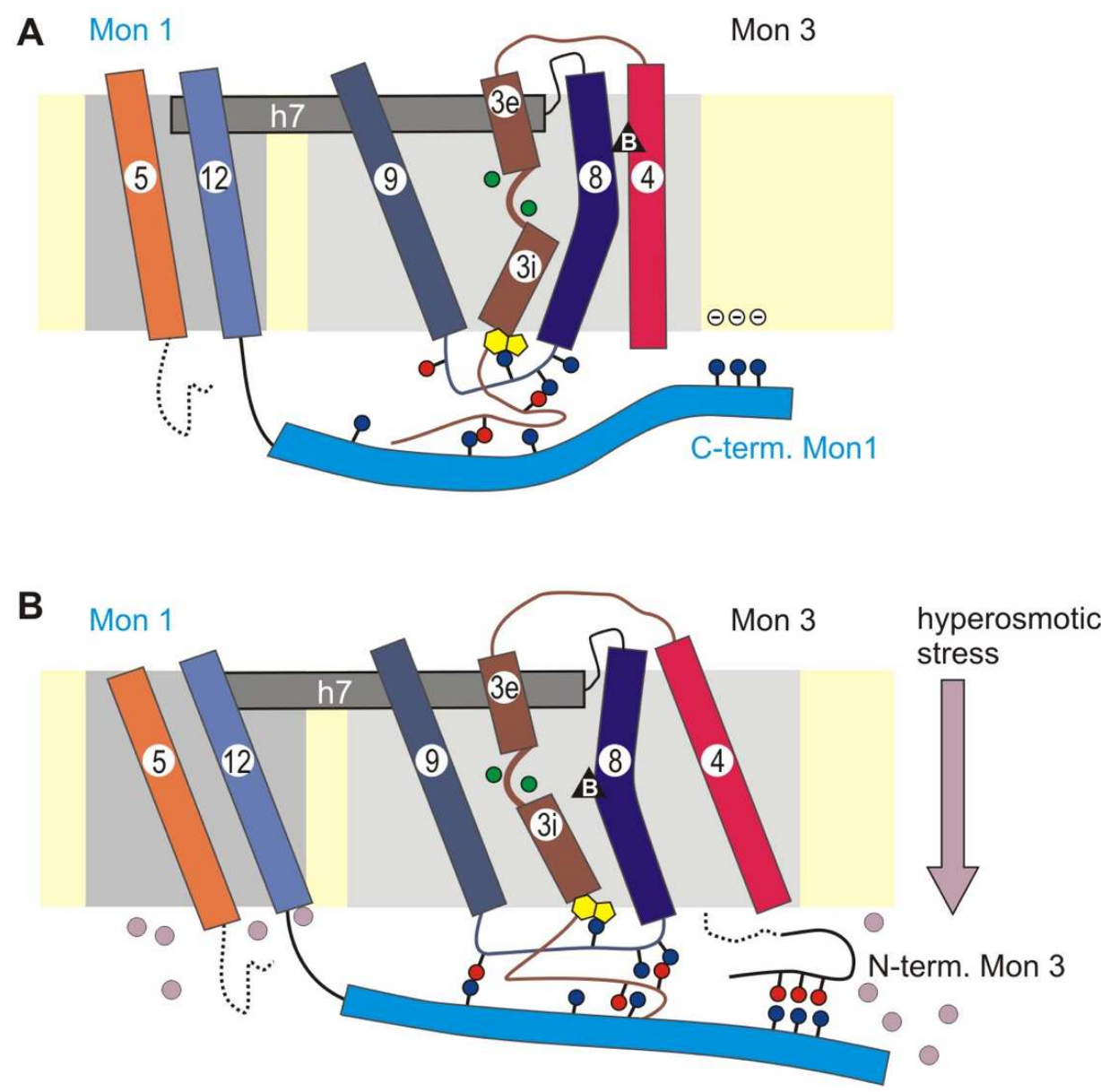

$422 \times 392 \mathrm{~mm}(72 \times 72 \mathrm{DPI})$ 


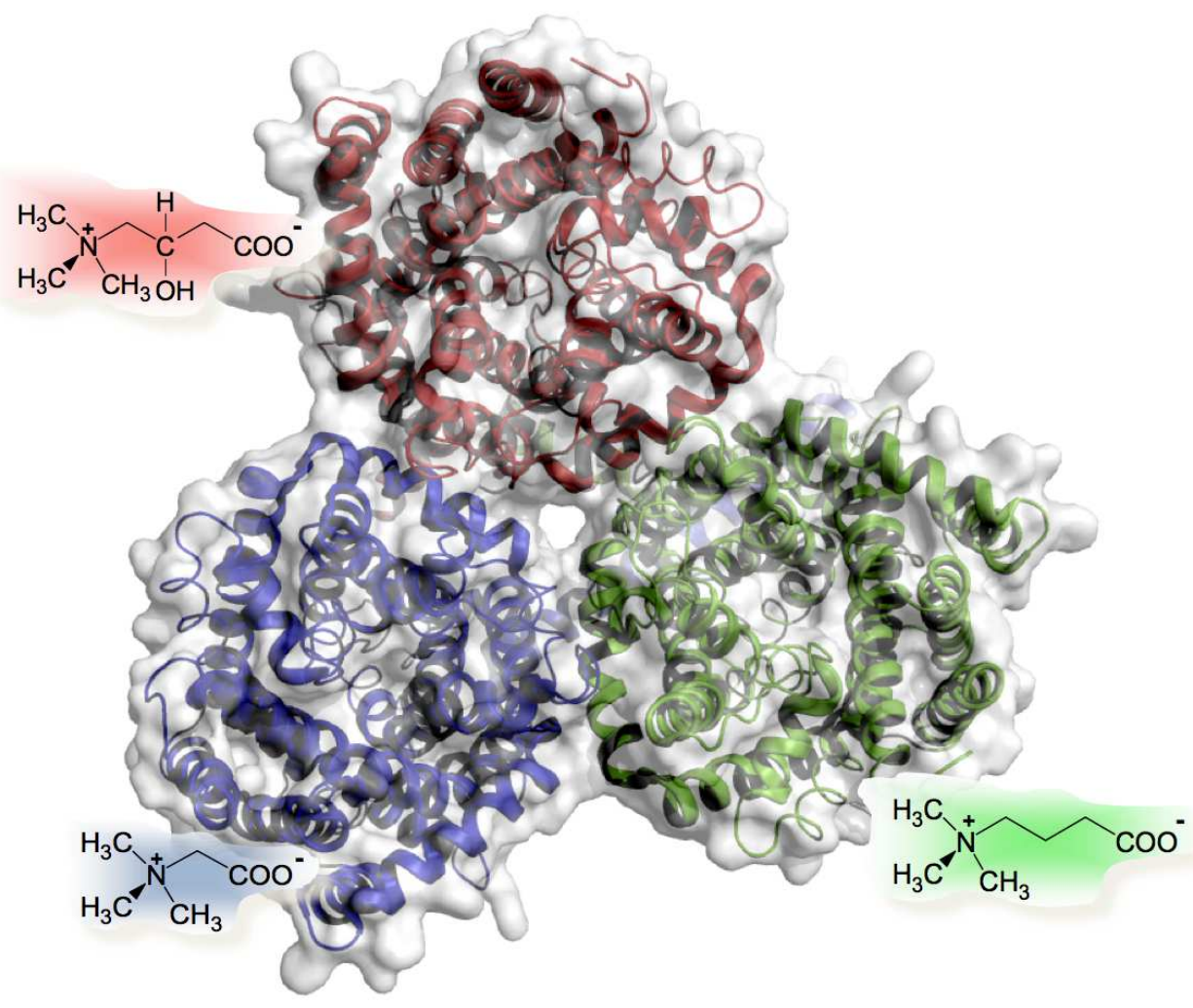

$423 \times 330 \mathrm{~mm}(72 \times 72$ DPI $)$ 


\section{Caption for the proposed cover picture:}

Top-down view on the trimer of the BetP BCCT-carrier and substrates for BetP (glycine betaine; blue) and the L-carnitine: $\gamma$-butyrobetaine (red and green, respectively) antiporter CaiT, a member of the BCCT-family. 